\title{
Thermal Stability of TiN Coated Cubic Boron Nitride Powder
}

\author{
Benjamin Hering ${ }^{1,2}$, Anne-Kathrin Wolfrum ${ }^{1, *}$, Tim Gestrich ${ }^{2}$ (D) and Mathias Herrmann ${ }^{2}$ (D) \\ 1 Institute for Materials Science, Dresden University of Technology, 01062 Dresden, Germany; \\ benjamin.hering@mailbox.tu-dresden.de \\ 2 Fraunhofer IKTS, Fraunhofer Institute for Ceramic Technologies and Systems, 01277 Dresden, Germany; \\ tim.gestrich@ikts.fraunhofer.de (T.G.); mathias.herrmann@ikts.fraunhofer.de (M.H.) \\ * Correspondence: anne-kathrin.wolfrum1@tu-dresden.de; Tel.: +49-351-2553-7206
}

Citation: Hering, B.; Wolfrum, A.-K.; Gestrich, T.; Herrmann, M. Thermal Stability of TiN Coated Cubic Boron Nitride Powder. Materials 2021, 14 , 1642. https://doi.org/10.3390/ ma14071642

Academic Editor: Maciej Sitarz

Received: 26 February 2021

Accepted: 24 March 2021

Published: 27 March 2021

Publisher's Note: MDPI stays neutral with regard to jurisdictional claims in published maps and institutional affiliations.

Copyright: (C) 2021 by the authors Licensee MDPI, Basel, Switzerland. This article is an open access article distributed under the terms and conditions of the Creative Commons Attribution (CC BY) license (https:// creativecommons.org/licenses/by/ $4.0 /)$.

\begin{abstract}
Wear-resistant, super hard ceramic composites based on cubic boron nitride (cBN) are of great interest to industry. However, $\mathrm{cBN}$ is metastable under sintering conditions at normal pressure and converts into the soft hexagonal $\mathrm{BN}(\mathrm{hBN})$. Therefore, efforts are being made to avoid this process. Besides short sintering times, the use of coated cBN-particles is a way to minimize this process. Therefore, the thermal stability of TiN coated cBN powders in high purity argon and nitrogen atmospheres up to temperatures of $1600{ }^{\circ} \mathrm{C}$ was investigated by thermogravimetry, X-ray phase analysis, scanning electron microscopy and Raman spectroscopy. The TiN coating was prepared by the atomic layer deposition (ALD)-method. The investigations showed that the TiN layer reacts in Ar at $\mathrm{T} \geq 1200{ }^{\circ} \mathrm{C}$ with the $\mathrm{cBN}$ and forms a porous $\mathrm{TiB}_{2}$ layer. No reaction takes place in nitrogen up to temperatures of $1600{ }^{\circ} \mathrm{C}$. Nevertheless, the 20 and $50 \mathrm{~nm}$ thin coatings also undergo a recrystallization process during heat treatment up to temperatures of $1600^{\circ} \mathrm{C}$.
\end{abstract}

Keywords: cubic boron nitride; cBN; titanium nitride; TiN; coating; thermal stability; hexagonal boron nitride; hBN; phase transformation; microstructure

\section{Introduction}

Due to the increasing need for wear-resistant components, the development of such ceramic composites is of great interest. Possible candidates are diamond or cubic boron nitride (cBN)-based ceramic composites. Because of the metastability of diamond and $\mathrm{cBN}$ under normal pressure and higher temperatures, $\mathrm{cBN}$-ceramic and diamond-ceramic matrix composites are mostly produced under high-pressure conditions up to now. This results in restrictions in geometry and costs. Therefore different attempts were carried out to produce $\mathrm{cBN}$-based ceramic composites, to find sintering conditions for manufacturing at low pressure and evaluating the properties of these composites with cubic boron nitride [1-9].

New sintering techniques like field-assisted sintering technology (FAST), also known as spark plasma sintering (SPS) or pulsed electric current sintering (PECS), allow a fast densification of these composites. The aim of such fast pressure-assisted densification methods is to prevent the transformation of the $\mathrm{cBN}$ into the hexagonal $\mathrm{BN}$ modification (hBN), which would otherwise lead to a significant decrease in hardness and wear resistance $[10,11]$.

The stability of $\mathrm{cBN}$ is still under discussion. Transformation temperatures of $\mathrm{cBN}$ to hBN from $0 \mathrm{~K}$ up to $1300{ }^{\circ} \mathrm{C}$ were described (boundary of the thermodynamic stability at ambient pressure) [1,12-22]. The detailed review of the literature and the behavior in different ceramic composites [1,21-23] reveal, that the transformation temperature must be at least below $1100{ }^{\circ} \mathrm{C}$. The transformation is strongly influenced by kinetic factors.

Cahill et al. [24] heat-treated three cBN powders with a different particle size at ambient pressure under $1 \mathrm{~atm}$ helium for $8 \mathrm{~h}$ at temperatures between 1560 and $1660{ }^{\circ} \mathrm{C}$ to analyse the kinetics and mechanism of $\mathrm{cBN}$ to hBN transformation. The powders with 
2-4 $\mu \mathrm{m}$ and $35-45 \mu \mathrm{m}$ cBN particles showed a start of cBN/hBN transformation at $1580{ }^{\circ} \mathrm{C}$. The $c B N$ powder with $<0.5 \mu \mathrm{m}$ particle sizes had a transformation starting temperature at $1560{ }^{\circ} \mathrm{C}$. Using SEM and TEM, the morphology of the $\mathrm{hBN}$ growing showed differences between the various particle sizes, which is attributed to a reduction in nucleation site availability. They concluded that small amounts of impurities or fluxes can lower the starting temperature of the $\mathrm{cBN} / \mathrm{hBN}$ transformation strongly.

Wolfrum et al. [23] investigated the thermal stability of a pure and a partially oxidized $\mathrm{cBN}$ powder at a temperature of $1550{ }^{\circ} \mathrm{C}$. The pure powder showed no evidence of $\mathrm{hBN}$ formation whereas the oxidized powder exhibited a significant formation of $\mathrm{hBN}$ on the surface of the $\mathrm{CBN}$ particles. Additional investigations of the transformation of $\mathrm{CBN}$ in different glass- and $\mathrm{Si}_{3} \mathrm{~N}_{4}$-matrices proof that the transformation is accelerated by a liquid oxide or oxynitride phase [23].

Due to these results [23], Wolfrum [1] analyzed if a titanium coating on cBN particles could suppress the $\mathrm{hBN}$ formation during sintering of SiAlON-cBN composites. However, the titanium coating proved to be unstable, reacted into TiN, resulting in a porous interlayer. This layer was not able to prevent the $\mathrm{hBN}$ formation during sintering of SiAlON-cBN composites by FAST method.

The influence of $\mathrm{Ni}[25,26]$ and $\mathrm{SiO}_{2}$ [27] coatings on the transformation behavior of cBN particles was investigated to avoid the $\mathrm{hBN}$ transformation during the SPS-process. At a sintering temperature of $1400^{\circ} \mathrm{C}$ no hBN formation could be detected.

Hotta et al. [28] have sintered TiN-cBN-composites using FAST method. The results of the XRD measurements show that no $\mathrm{hBN}$ was formed until a sintering temperature of $1650{ }^{\circ} \mathrm{C}$. However, in previous investigations of $\mathrm{Al}_{2} \mathrm{O}_{3}-\mathrm{CBN}$-composites a starting temperature of $\mathrm{hBN}$ formation at $1400{ }^{\circ} \mathrm{C}$ was observed [29]. The starting temperature of $1650{ }^{\circ} \mathrm{C}$ was determined for $\mathrm{hBN}$ formation in a monolithic $\mathrm{cBN}$ body by the same authors. This is the same as for the TiN-cBN-composites [30]. In all TiN-cBN composites sintered in a temperature range of $1600-1800{ }^{\circ} \mathrm{C}$ a small amount of $\mathrm{TiB}_{2}$ could be found via XRD.

Kitiwan et al. [31] used FAST for the densification of hBN-TiN composites between 1700 and $2000{ }^{\circ} \mathrm{C}$. Up to $1700{ }^{\circ} \mathrm{C}$ no formation of $\mathrm{TiB}_{2}$ was observed indicating the high kinetic stability of the metastable hBN-TiN mixture.

Xie et al. [32] produced TiN-cBN composites with high-pressure high-temperature method (e.g., $1450-1550{ }^{\circ} \mathrm{C} ; 6 \mathrm{GPa}$ ). Only traces of $\mathrm{TiB}_{2}$ were observed.

Umer et al. [33] sintered also with high-pressure high-temperature method cBN composites with sol gel coated TiN-cBN powders (details of the sol gel TiN coating process can be found in a previous work of Umer et al. [34]) densified with $\mathrm{TiN}$ and $\mathrm{Al}$ at $1500{ }^{\circ} \mathrm{C}$ and $6 \mathrm{GPa}$. The XRD pattern showed only traces of $\mathrm{TiB}_{2}$. However, the interaction was slightly higher for the coated powder in comparison to the mixture of uncoated cBN and TiN powders. The sol gel TiN coating of cBN powders was not dense [34]. Similar results we found in own investigations concerning sol gel coatings.

With the results of Hotta [28,30] and the comparisons worked out by Wolfrum [1] and Zhang et al. [9] concerning the influence of different matrix materials on the transformation temperature of cBN within the FAST process, it is shown that a TiN-based matrix neither contributes to an acceleration nor to a retardation of $h B N$ formation. Based on this, a dense and homogeneous TiN coating on the $\mathrm{CBN}$ particles could lead to the stabilization of the cBN modification during the sintering process using FAST, even with the presence of a liquid phase.

Therefore, in the present work, the stability of titanium nitride (TiN) coatings on cBN particles and its influence on the $\mathrm{cBN}$ to hBN-transformation was investigated using thermogravimetric analyses followed by FESEM and XRD analysis and Raman spectroscopy.

\section{Materials and Methods}

Three cBN powders with an average particle size of $20 \mu \mathrm{m}$ B20, B21 and C41 from Vollstädt-Diamant GmbH (Seddiner See, Germany) were used. FESEM Micrographs of each powder as received is shown in Figure 1. The TiN coating was prepared with a Fraunhofer IKTS intern developed coating system based on the atomic layer deposition 
(ALD) on powder B20. For the coating, the as-received powder and a powder heat-treated at $1000{ }^{\circ} \mathrm{C}$ in hydrogen atmosphere directly prior to the coating were used. In the further course of the work, the coated powder without pre-treatment will be referred to as BT powder and the coated powder cBN with hydrogen pre-treatment as BTV. Details of the coating methods are explained in [35-38].

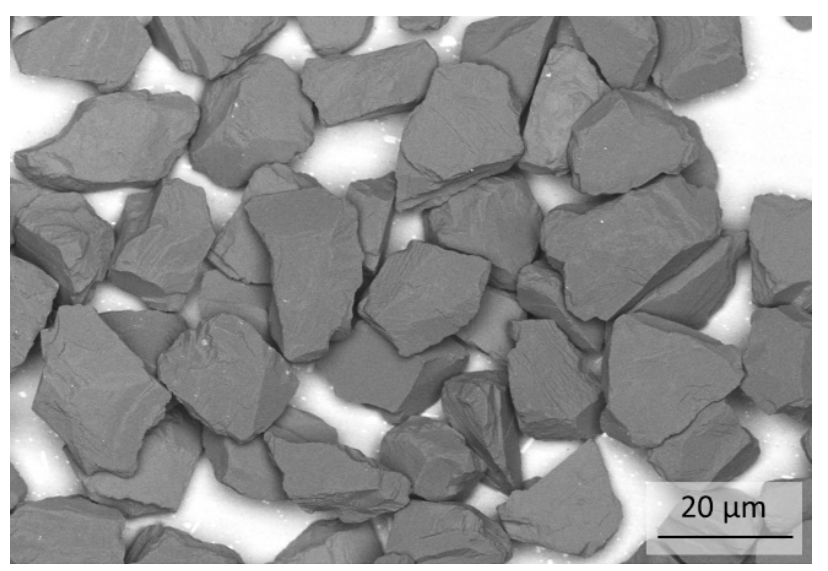

(a)

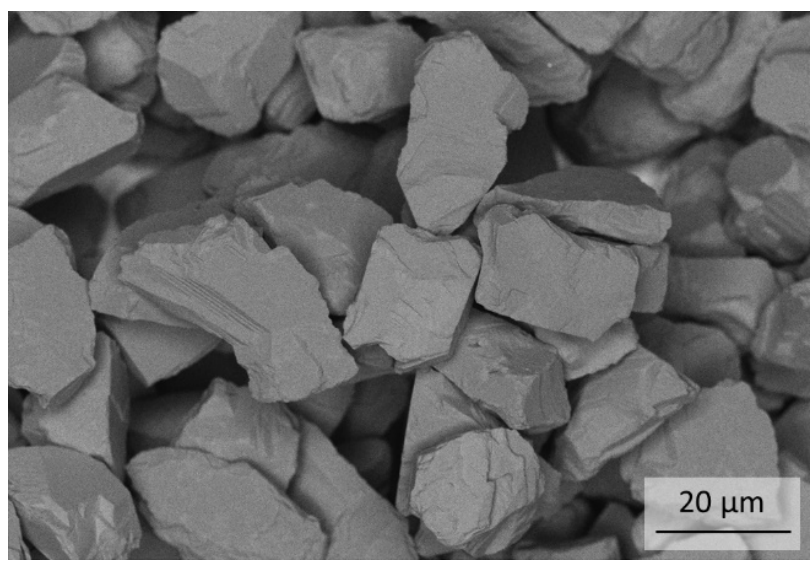

(b)

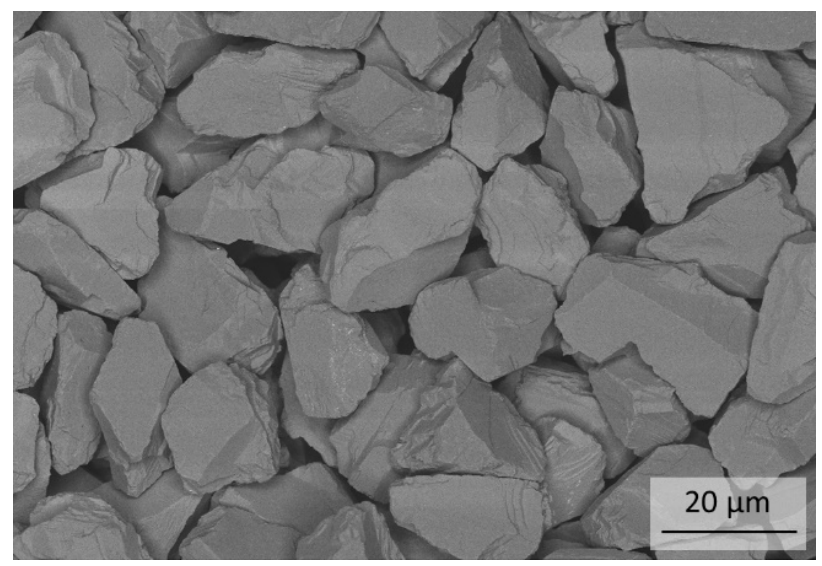

(c)

Figure 1. FESEM micrographs of the $c B N$ powders in the initial state (as-received state); (a) cBN-B20; (b) cBN-B21; (c) cBN-C41.

Prior to the analysis of the thermal stability of the different cBN powders, they were analyzed regarding their oxygen content through hot gas extraction (LECO TCH 600, LECO Corporation, St. Joseph, MI 49085, USA) and their metallic impurities by X-ray fluorescence analysis (XRF) (Bruker S8 Tiger, Bruker AXS, Karlsruhe, Germany). The phase content before and after thermal treatment of the powders was analyzed by X-ray diffraction (XRD) using a diffractometer (D8 Advance, Bruker AXS, Karlsruhe, Germany), operated with $\mathrm{Cu}-\mathrm{K} \alpha$ radiation with a LynxEye position-sensitive detector (PSD) over a two-theta range of $10-100^{\circ} 2 \theta$ with a step size of $0.02^{\circ} 2 \theta$. For the qualitative evaluation, the software DIFFRAC.EVA (Bruker AXS, Karlsruhe, Germany) and a PDF (Powder Diffraction File from the International Centre for Diffraction Database 2021) structure database were used. Quantitative evaluation was carried out using the Topas6.0 software (Bruker AXS, Karlsruhe, Germany).

The occurrence of hBN after heat treatment of the powders was analyzed using the Raman spectroscopy as well as the initial cBN powders for comparison. A LabRAM HR800 (Horiba Scientific Ltd., Bensheim, Germany) with a blue laser with a wavelength of $473 \mathrm{~nm}$ and an approximate measuring spot size of $0.8 \mu \mathrm{m}$ was used. 
Two field emission scanning electron microscopes (FESEM, Ultra 55 and NVision 40, Zeiss Ltd., Oberkochen, Germany) with an ESB (energy selective backscattered electrons) detector (Zeiss Ltd., Oberkochen, Germany) for material contrast and an SE2 (secondary electron) detector (Zeiss Ltd., Oberkochen, Germany) for topography contrast were used to investigate the microstructure of the TiN coated powders and the thermally treated cBN powders.

For characterizing the TiN coating thickness and their microstructure, TiN coated cBN particles were embedded in epoxy resin and cross-sections were prepared by broad ion beam polishing (BIB) using BalTec RES 101 (Bal-Tec AG, now: Leica Microsystems GmbH, Wetzlar, Germany) [39].

The thermal stability of the $\mathrm{CBN}$ powders was investigated using thermogravimetric analysis in a STA 429 CD with tungsten furnace (NETZSCH-Gerätebau GmbH, Selb, Germany) and graphite crucibles. A heating rate of $10 \mathrm{~K} / \mathrm{min}$ up to $1600^{\circ} \mathrm{C}$ and $10 \mathrm{~L} / \mathrm{h}$ argon or nitrogen flow were used. A holding time of $60 \mathrm{~min}$ at $1600{ }^{\circ} \mathrm{C}$ was applied. The cooling rate was $20 \mathrm{~K} / \mathrm{min}$. Only with the tungsten furnace is it possible to achieve the low oxygen partial pressures required for the experiments. The absolute masses of the analyzed powders by TG ranged from approximately 180 to $1000 \mathrm{mg}$ due to the different available masses after coating using the ALD process. The different mass could be also the reason of the slightly different noise of the mass change signal.

The heat treatment temperature was chosen because at $1550{ }^{\circ} \mathrm{C}$ uncoated $\mathrm{cBN}$ particles showed no transformation in earlier experiments [23]. Therefore, it was decided to increase the temperature to determine the protective effect and stability of the coatings. However, the densification of cBN ceramic matrix composites usually takes place below $1600{ }^{\circ} \mathrm{C}$. Therefore, we choose this temperature for the experiment.

Thermodynamic calculations were carried out using FACTSAGE 8.0 (CRCT, Montreal, QC, Canada and GTT-Technologies, Herzogenrath, Germany) [40]. The database does not contain the data of $\mathrm{cBN}$. Therefore the data in $[1,23]$ were used for $\mathrm{cBN}$.

\section{Results}

\subsection{Characterization of the Initial cBN Powders}

The properties of the powders are given in Table 1. The thickness of the coating depends on the pretreatment. Without hydrogen pretreatment, a thickness of $50 \mathrm{~nm}$ was determined by FESEM micrographs of cross-sections of the BT powder. For the BTV powder with hydrogen pretreatment, only a thickness of $20 \mathrm{~nm}$ was observed. This could be caused by the different nucleation rate of the TiN coating. The different coating thickness can also be confirmed by results of the quantitative analysis from XRF and XRD, as only a TiN mass fraction of approximately $1.3 \mathrm{wt}$. \% was determined for the BTV powder and approximately $2.3 \mathrm{wt}$ \% for the BT powder.

Table 1. Properties of the used cubic boron nitride (cBN) powders and TiN coated cBN powders regarding oxygen content, metallic impurities, coating content and coating thickness (the TiN content was determined by XRF measurement of Ti and XRD).

\begin{tabular}{|c|c|c|c|c|c|c|c|}
\hline \multirow{2}{*}{$\begin{array}{c}\text { cBN- } \\
\text { Powder }\end{array}$} & \multirow{2}{*}{$\begin{array}{c}\text { Oxygen } \\
\text { Content (wt. \%) }\end{array}$} & \multicolumn{4}{|c|}{ Metallic Impurities (wt. \%) } & \multirow{2}{*}{$\begin{array}{c}\text { TiN-Coating } \\
\text { Content (XRF/XRD) } \\
(\text { wt. } \%)\end{array}$} & \multirow{2}{*}{$\begin{array}{l}\text { TiN-Coating } \\
\text { Thickness } \\
\text { (nm) }\end{array}$} \\
\hline & & $\mathrm{Fe}$ & $\mathrm{Si}$ & $\mathrm{Cl}$ & $\mathrm{Cr}$ & & \\
\hline B20 & $0.122 \pm 0.042$ & 0.0028 & 0.03 & - & - & - & - \\
\hline B21 & $0.101 \pm 0.015$ & 0.0027 & 0.02 & - & - & - & - \\
\hline C41 & $0.113 \pm 0.023$ & 0.0028 & 0.02 & - & - & - & - \\
\hline BT & $0.170 \pm 0.023$ & 0.02 & 0.03 & 0.05 & 0.0085 & $2.3 / 2.3 \pm 0.1$ & 50 \\
\hline BTV & $0.135 \pm 0.032$ & 0.01 & 0.03 & 0.02 & 0.0080 & $1.4 / 1.3 \pm 0.1$ & 20 \\
\hline
\end{tabular}

The XRD pattern in Figure 2 of the starting powders reveals besides cBN (ICDD card: 00-035-1365) the TiN (ICDD card: 01-087-0627) formation. 


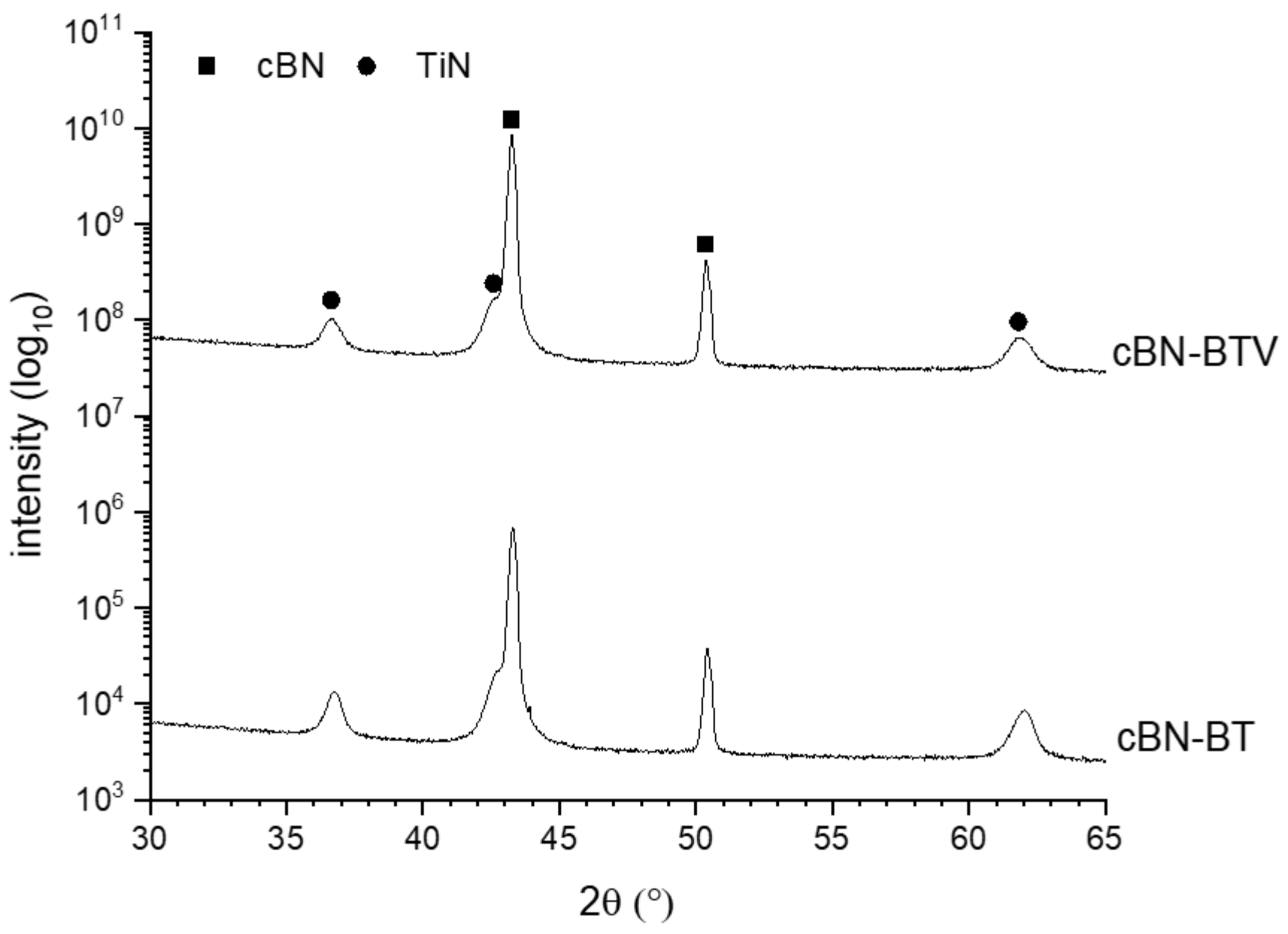

Figure 2. XRD-pattern of the TiN coated $\mathrm{cBN}$ powders BT and BTV.

The FESEM micrograph of Figure 3a shows the surface of a cBN particle of the uncoated B21 powder and Figure 3b-e show different TiN coated particles of the BT powder before the heat treatment at $1600{ }^{\circ} \mathrm{C}$. No impurities at the surface of the uncoated cBN B21 could be found. For the TiN coated powder BT it can be proven, that the cBN particles are mostly completely coated with TiN. Only a few particles exhibit a partly damaged coating as it is shown in Figure $3 \mathrm{c}$ with topography contrast and Figure $3 \mathrm{~d}$ with material contrast respectively, probably due to contact with another $\mathrm{cBN}$ particle during the coating process. The microstructure of the TiN coating in more detail is demonstrated in Figure 3e.

Figure 4 shows the cross-sections of the TiN coated cBN powders BT and BTV. Both powders exhibit a dense and homogeneous TiN layer on the cBN particles. Every cBN particle could be coated with TiN, while a few particles show thicker coatings (see Figure $4 a, c)$. It was observed that the BT powder has a thicker TiN coating (approximately $50 \mathrm{~nm}$ ) than the BTV powder (approximately $20 \mathrm{~nm}$ ) (see Table 1).

\subsection{Thermal Stability of the cBN Powders}

The results of the thermogravimetric analysis in argon atmosphere are given in Figure 5 and in nitrogen atmosphere in Figure 6. It must be considered that the absolute initial masses for the thermogravimetric investigation differs in a wide range (from approximately $180 \mathrm{mg}$ to approximately $1000 \mathrm{mg}$ ). A lower initial mass leads to a higher relative noise of the mass change signal.

A significant loss of mass for the TiN coated $\mathrm{CBN}$ powders BT and BTV were observed during heat treatment under argon atmosphere (see also Table 2), whereas the uncoated powders B21 and C41 have a mass loss of only 0.04 wt. \% (Figure 5a). In Figure 5b a small 
section of Figure 5a is plotted against temperature to show the onset of mass loss. The mass loss of the uncoated powders starts at $800{ }^{\circ} \mathrm{C}$ for $\mathrm{C} 41$ and at $1200{ }^{\circ} \mathrm{C}$ for B21. This mass loss is most probably caused by the evaporation of boric acid and $\mathrm{B}_{2} \mathrm{O}_{3}$ existing on the surface of the particles.

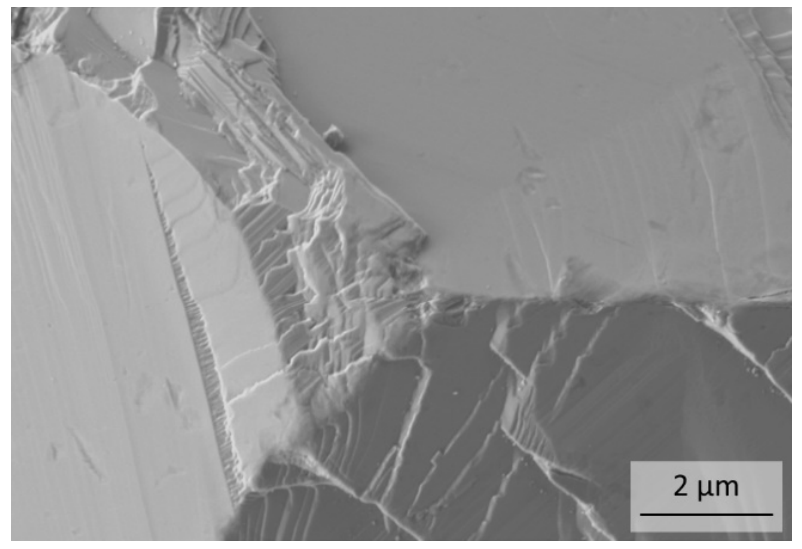

(a)

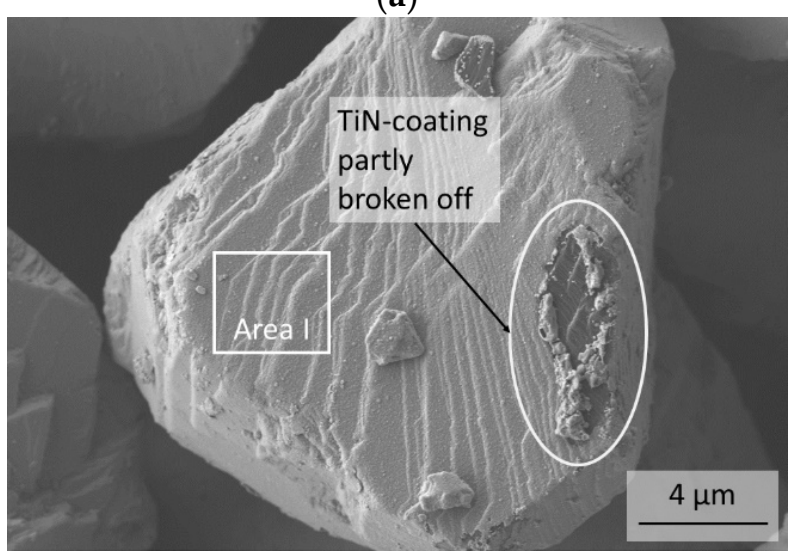

(c)

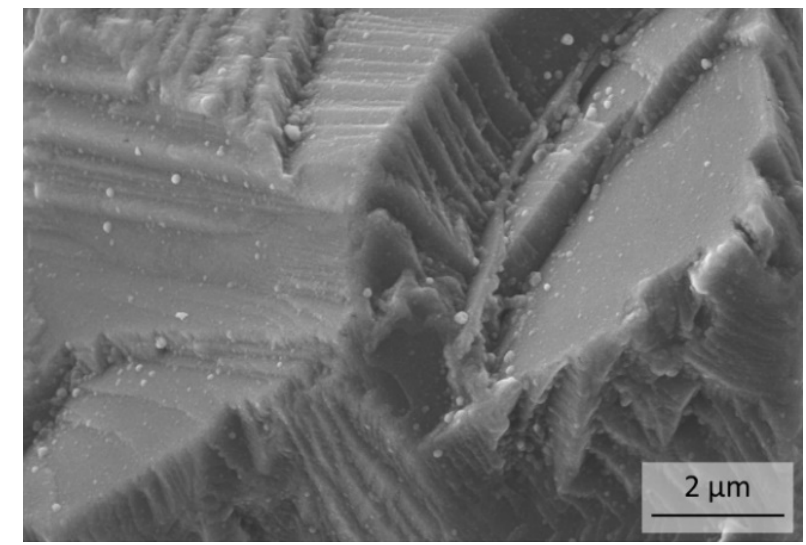

(b)

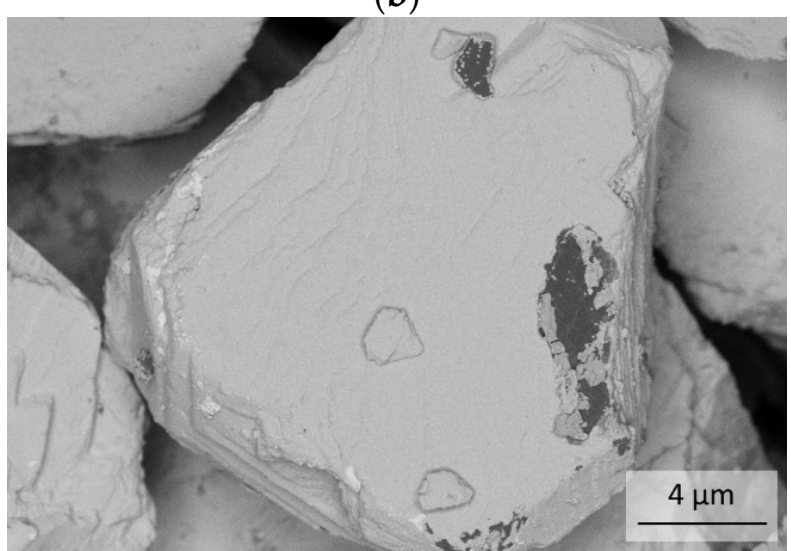

(d)

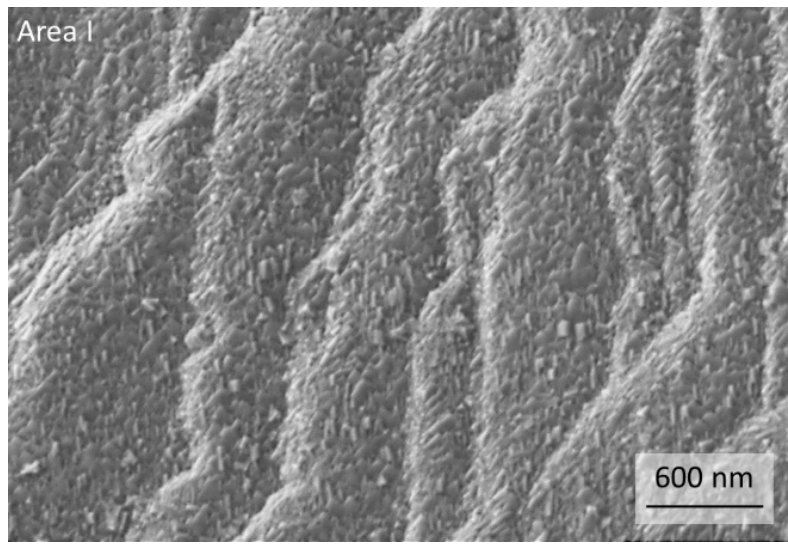

(e)

Figure 3. FESEM micrographs of uncoated cBN particles B21 (a) and coated with TiN BT (b-e) before the heat treatment. (d) same area as (c) with material contrast (energy selective backscattered electrons (ESB)-detector); (e) is a section (Area I) of micrograph (c) to reveal the microstructure of the TiN coating in more detail. 


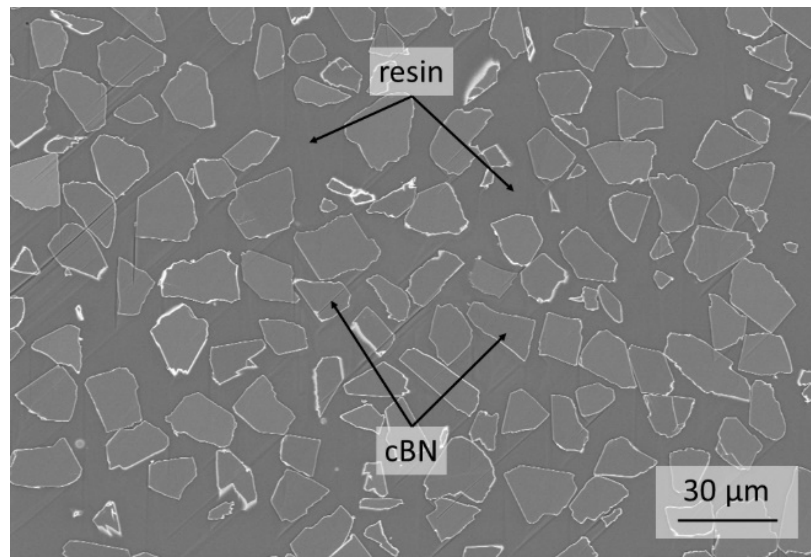

(a)

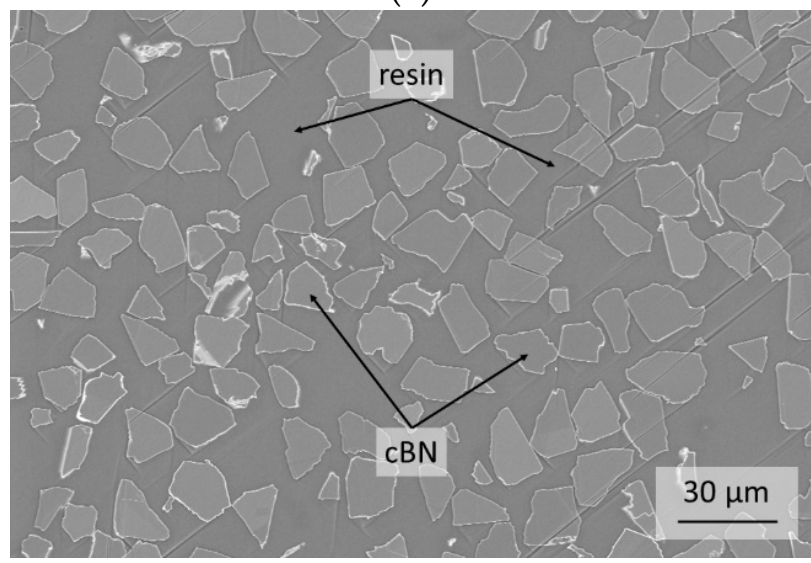

(c)

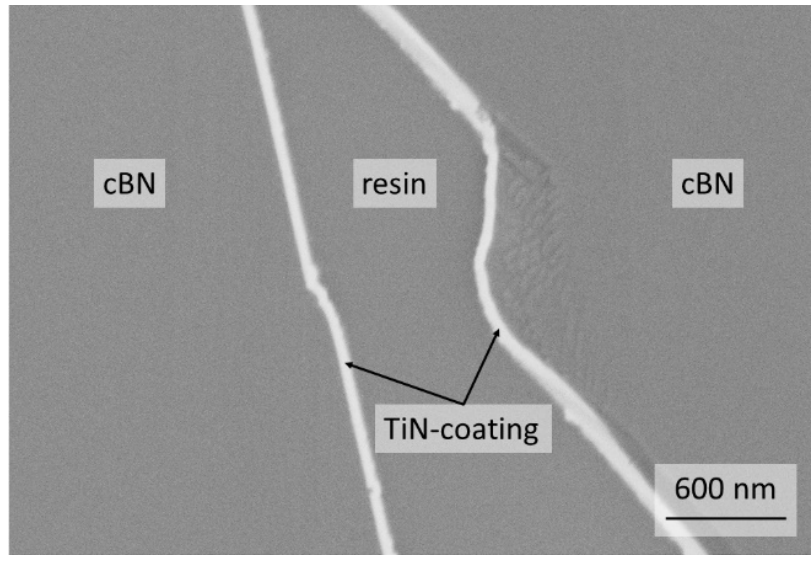

(b)

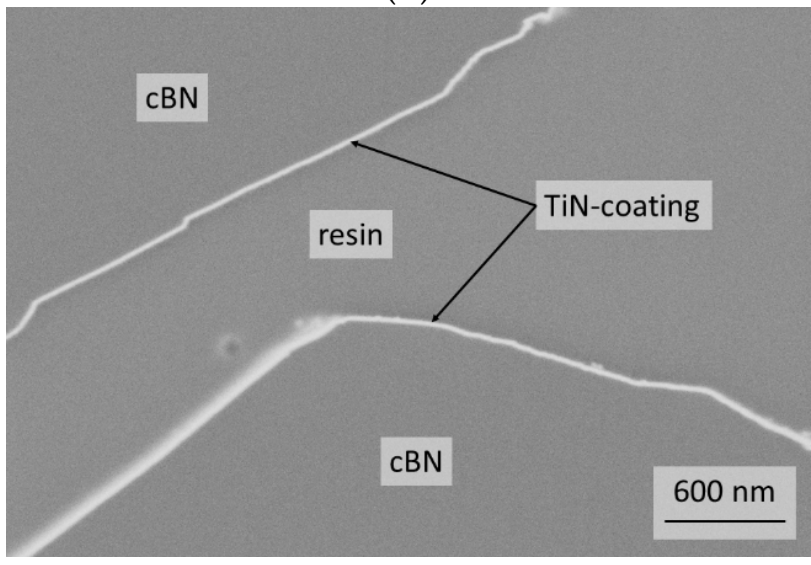

(d)

Figure 4. Cross-sections via FESEM (material contrast) of the (a,b) TiN-coated BT and (c,d) BTV powder.

The mass change of the BT powder is small but complex at lower temperatures. This could be caused by the interaction with the still existing impurities on the surface. The BTV powder behaves like that of C41 at temperatures up to $120{ }^{\circ} \mathrm{C}$. However, the weight change in this temperature area is less than $0.01 \mathrm{wt}$. \%. An acceleration of the weight loss starts for the coated powders BT and BTV at 1210 and $1175^{\circ} \mathrm{C}$ respectively. This weight loss only stops at the end of the isothermal holding time. At the end of the holding time, the weight loss of the BTV powder is $1.58 \mathrm{wt}$. \%, which is higher than for the BT powder (1.01 wt. \%) (see Table 2).

Table 2. Mass losses of the cBN-powders after thermogravimetric analysis under argon and nitrogen atmosphere up to a temperature of $1600^{\circ} \mathrm{C}$.

\begin{tabular}{cccc}
\hline cBN-Powder & Coating & Atmosphere & $\begin{array}{c}\text { Mass Loss } \\
\text { (wt. \%) }\end{array}$ \\
\hline B21 & - & & 0.04 \\
C41 & - & argon & 0.04 \\
BT & TiN & & 1.58 \\
BTV & TiN & nitrogen & 1.01 \\
\hline B21 & - & & 0.02 \\
BT & $\mathrm{TiN}$ & 0.17 \\
\hline
\end{tabular}

A different behavior is observed in a nitrogen atmosphere (Figure 6a). The maximum mass loss for the TiN coated powder BT is only $0.17 \mathrm{wt}$. \%, what is still slightly higher than for the uncoated powder B21 (0.02 wt. \%). However, this is much less than for the coated BT powder tempered under argon (1.01 wt. \%). Figure $6 \mathrm{~b}$ also display the mass loss 
against temperature. It is obvious, that a very low loss of mass for the BT powder starts at $520^{\circ} \mathrm{C}$ and for the uncoated B21 powder at $1400^{\circ} \mathrm{C}$.

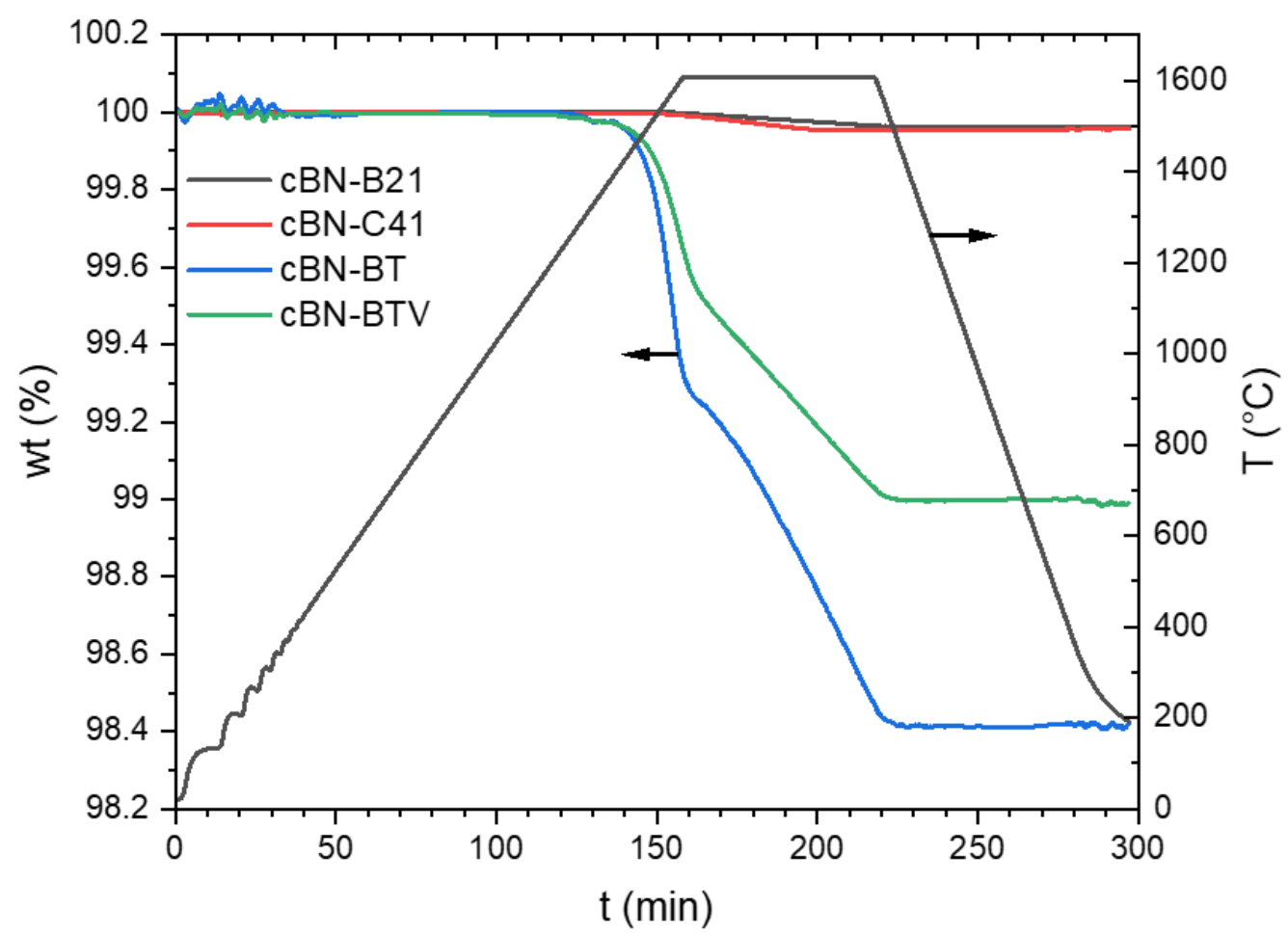

(a)

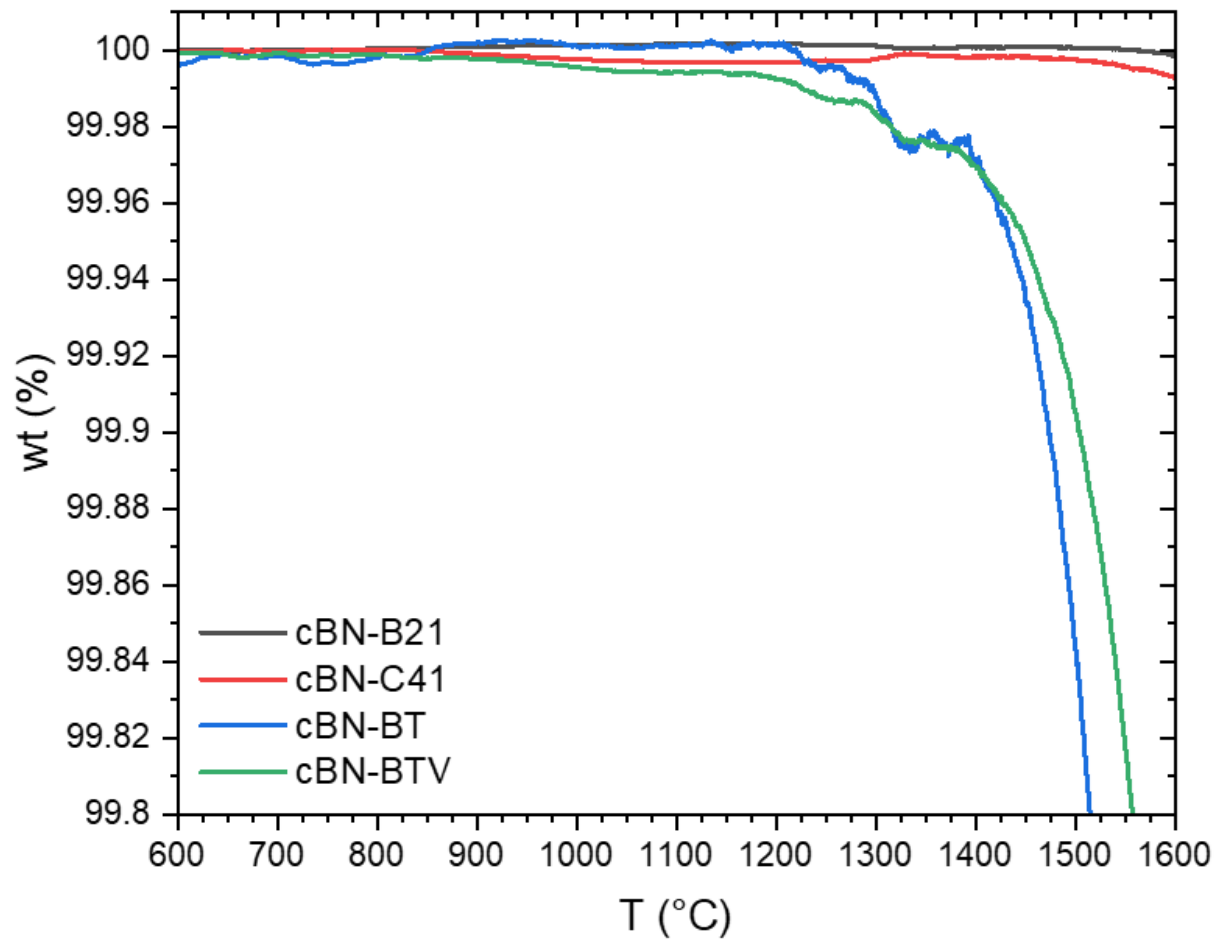

(b)

Figure 5. (a) Mass loss during the thermogravimetric analysis of the cBN powders B21, C41, BT and BTV under argon atmosphere and (b) mass loss as a function of temperature of the same (data of Figure $5 \mathrm{a}$ ). 


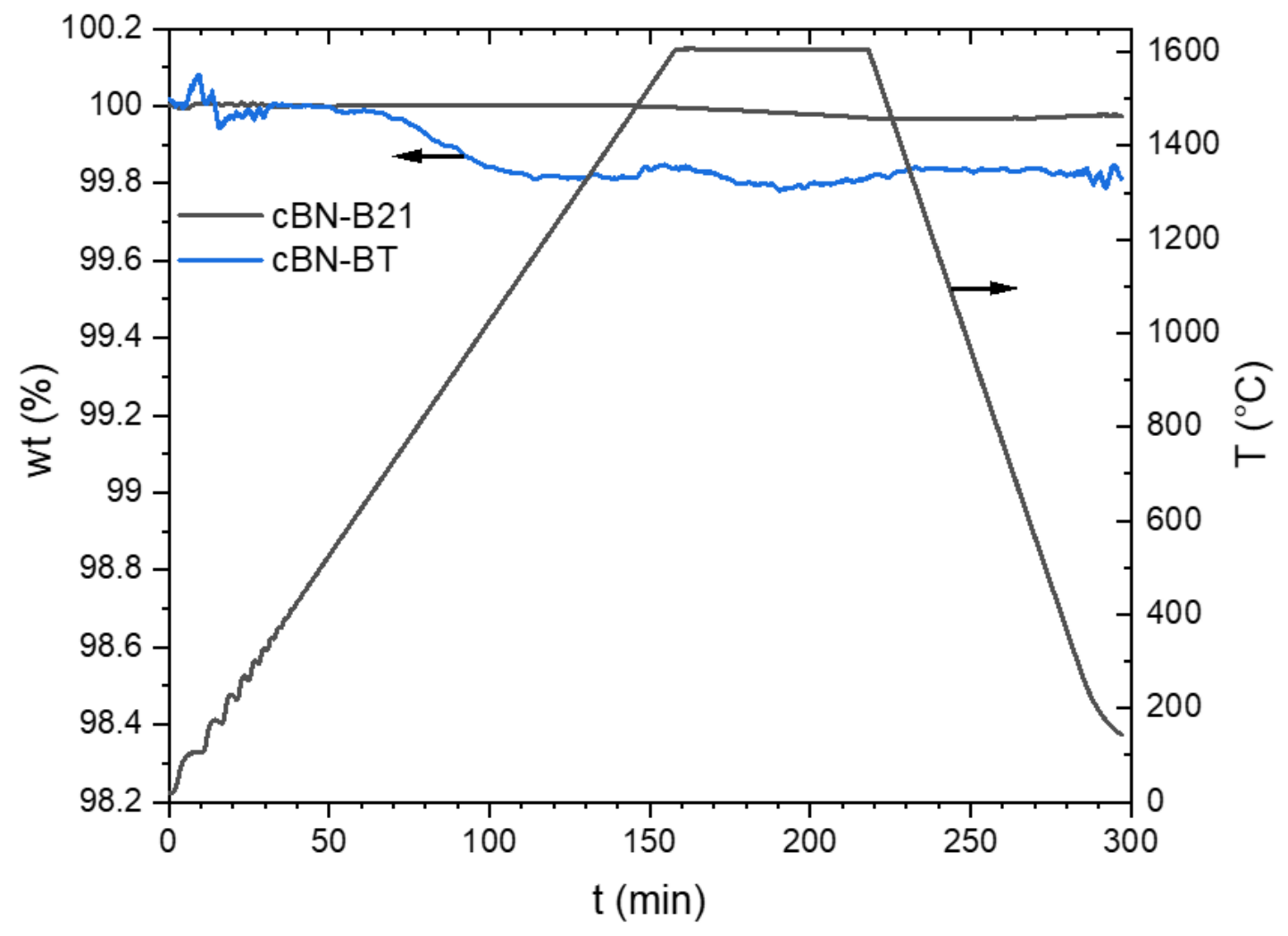

(a)

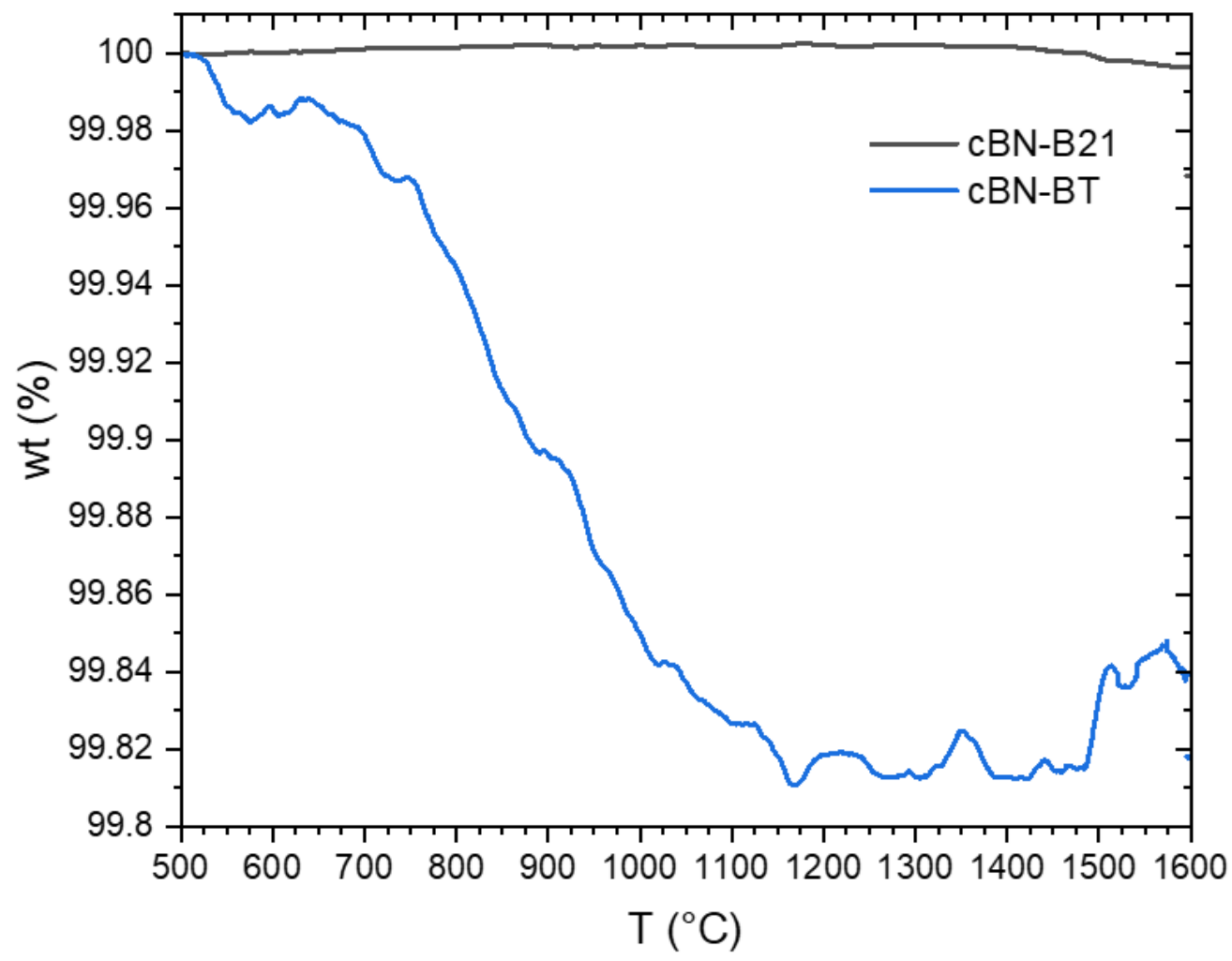

(b)

Figure 6. (a) Mass loss during thermogravimetric analysis under a nitrogen atmosphere of the cBN powders B21 und BT and (b) mass loss as a function of temperature of the same. 
The results of the $\mathrm{XRD}$ analysis of the $\mathrm{cBN}$ powders tempered under argon at $1600^{\circ} \mathrm{C}$ are represented in Figure 7. The cBN peaks (ICDD card: 00-035-1365) are clearly visible in all four powders as well as the broad peaks corresponding to the hBN modification (ICDD card: 01-085-1068). The hBN peaks of the uncoated powders (B21, C41) have a much higher intensity than those of the coated powders (BT, BTV), whereas the C41 powder exhibits the highest hBN amount. For the TiN coated powders, the TiN-phase observed in the initial state disappeared nearly completely after heat treatment. Obviously, it has converted into $\mathrm{TiB}_{2}$ (ICDD card: 01-085-2083).

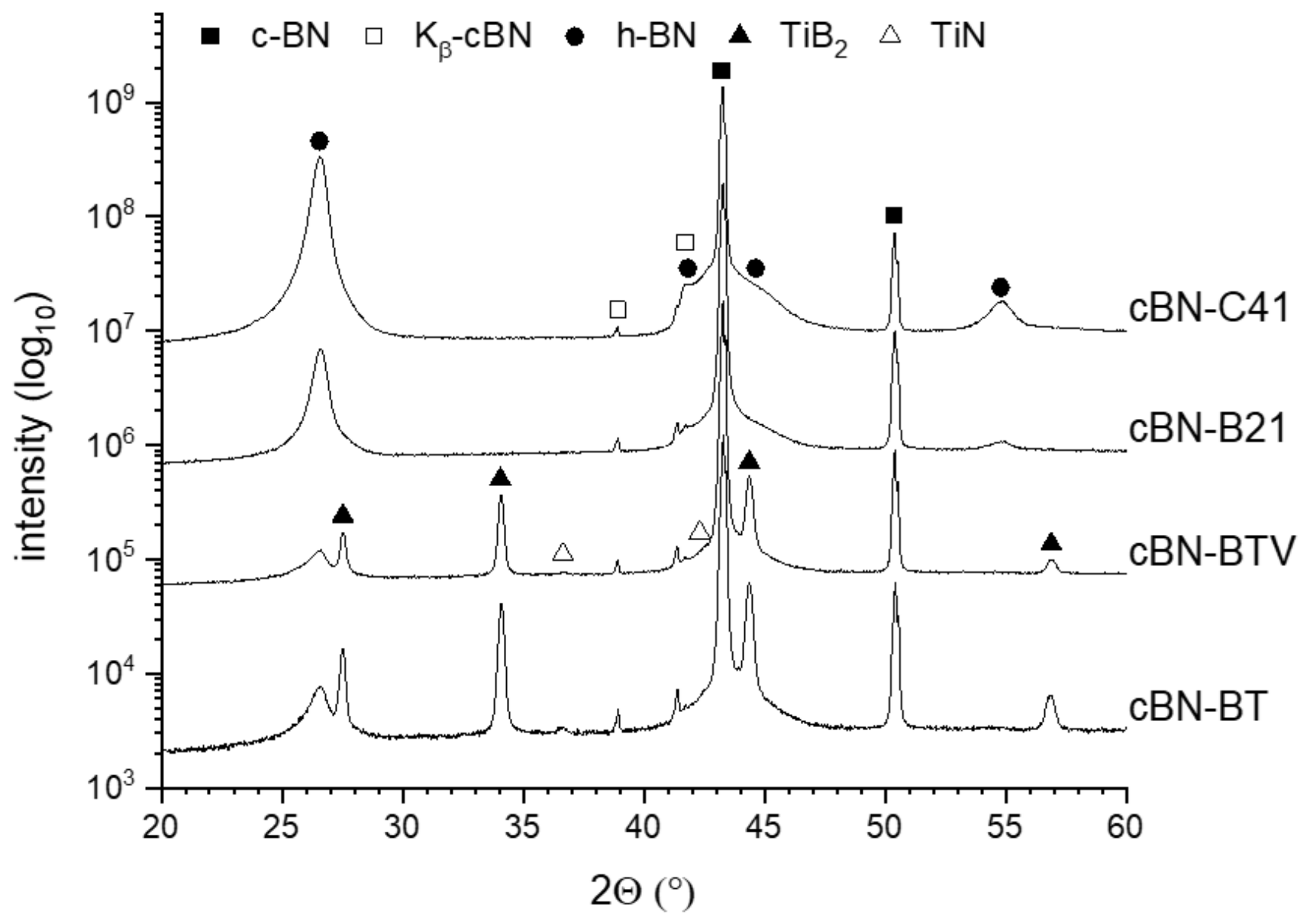

Figure 7. XRD patterns of the investigated $\mathrm{cBN}$ powders tempered at $1600{ }^{\circ} \mathrm{C}$ under an argon atmosphere (the logarithmic scaling emphasizes the minor phases with low peak intensity).

The XRD patterns of the powders tempered under nitrogen shown in Figure 8 reveal the existence of cBN and hBN reflexes. However, the TiN phase (ICDD card: 01-087-0627) is stable under these conditions and no $\mathrm{TiB}_{2}$ phase was observed. The intensity of the formed $\mathrm{hBN}$ in the TiN coated cBN (BT) was lower compared to the uncoated powder B21.

The micrographs in Figure 9a-d show an overview of the surfaces of cBN particles of the uncoated C41 and B21 powder after the heat-treatment at $1600{ }^{\circ} \mathrm{C}$. Detailed investigations show the begining of the formation of a hBN layer on the surface (Figure $9 b, d$ ). The growth starts at edges and steps and continues from there over the surface. Edges and steps are probably the preferred nucleation sites.

Micrographs of the particle surface of the coated BT powder heat-treated in argon and in nitrogen are shown in Figure 10. The surface looks different in comparison to the initial state (Figure 3). The Figure 10a,b micrographs prove that the TiN phase transformed during the heat-treatment under argon into the $\mathrm{TiB}_{2}$ phase, which exhibits a different grain shape. Because of the transformation, pores were formed within the coating in which 
hexagonal boron nitride can be found as it is shown in Figure $10 \mathrm{~b}$ as dark grains. Due to this, the protection of the $\mathrm{cBN}$ particles by the coating cannot be achieved.

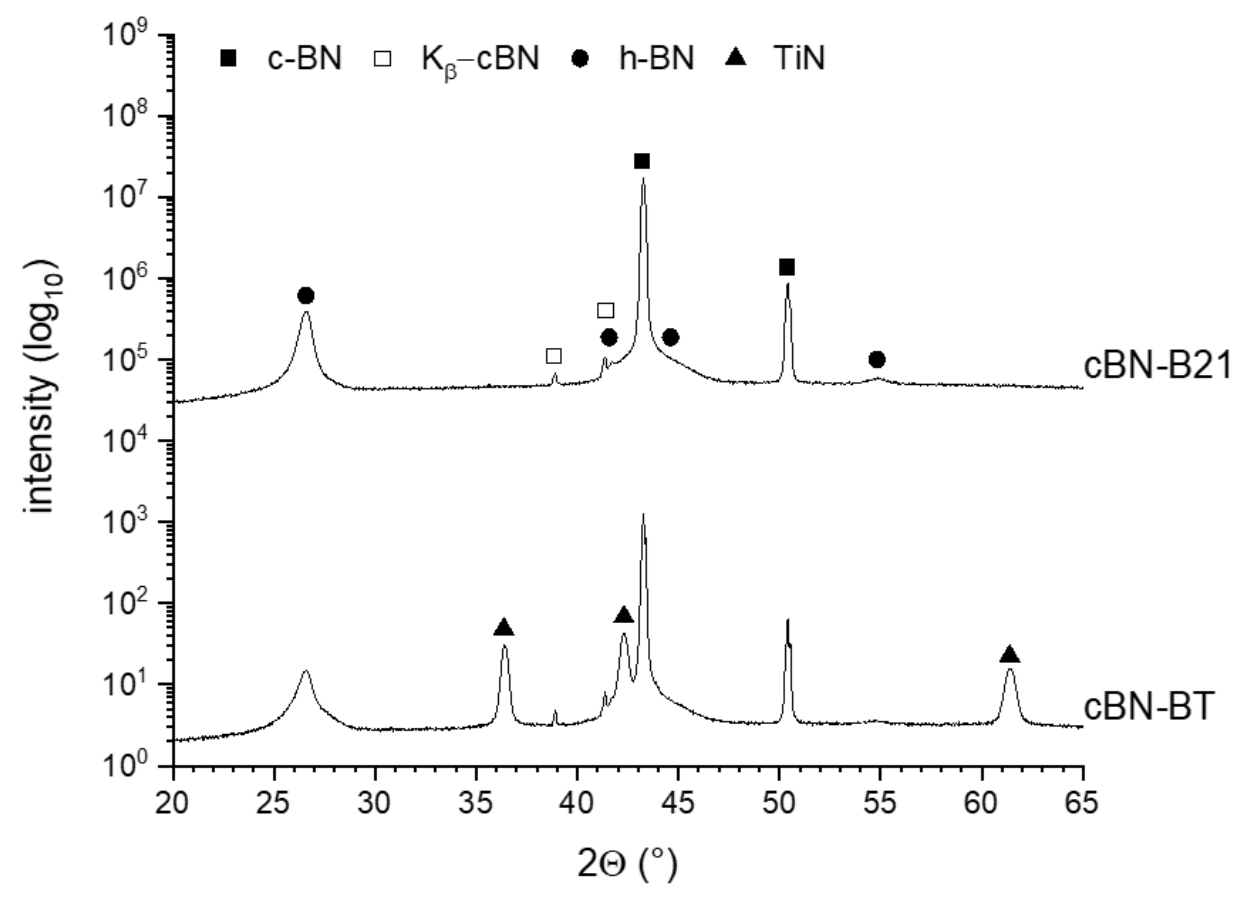

Figure 8. XRD patterns of the investigated $c B N$ powders tempered at $1600{ }^{\circ} \mathrm{C}$ under nitrogen (the logarithmic scaling emphasizes the minor phases with low peak intensity).

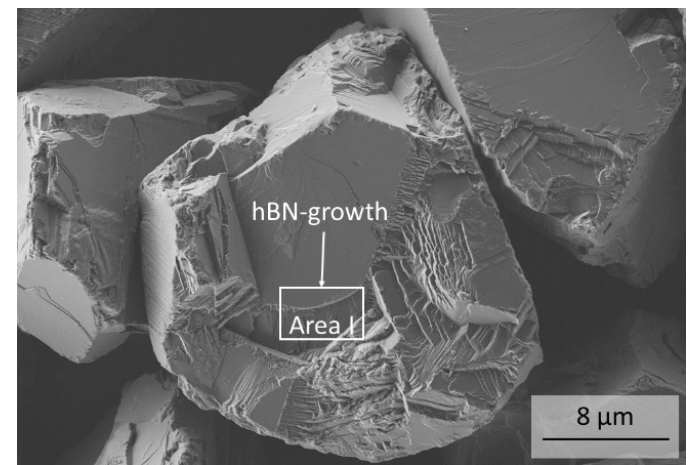

(a)

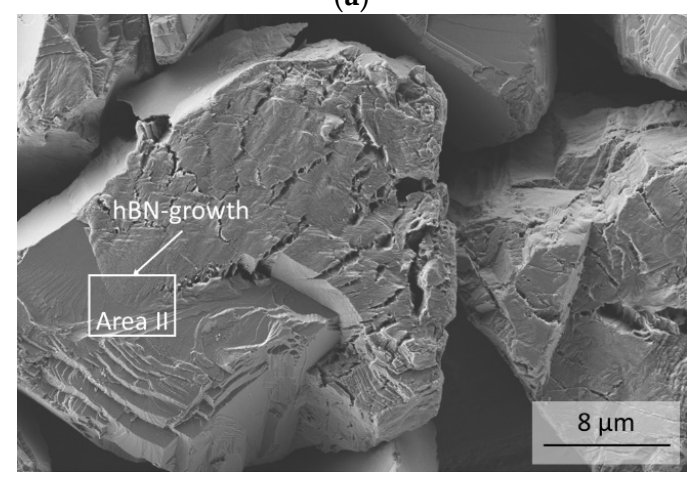

(c)

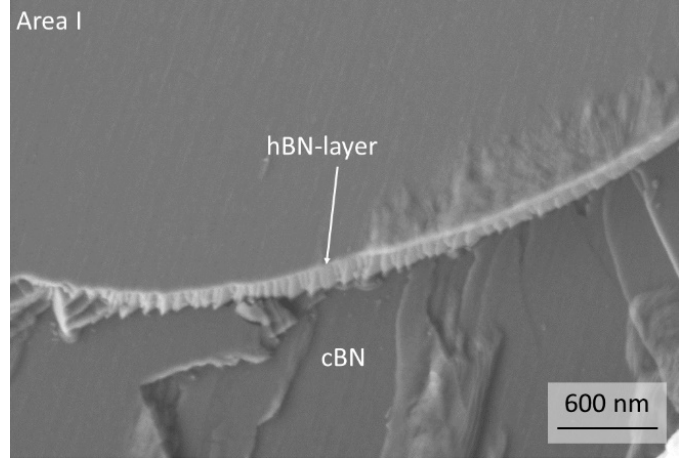

(b)

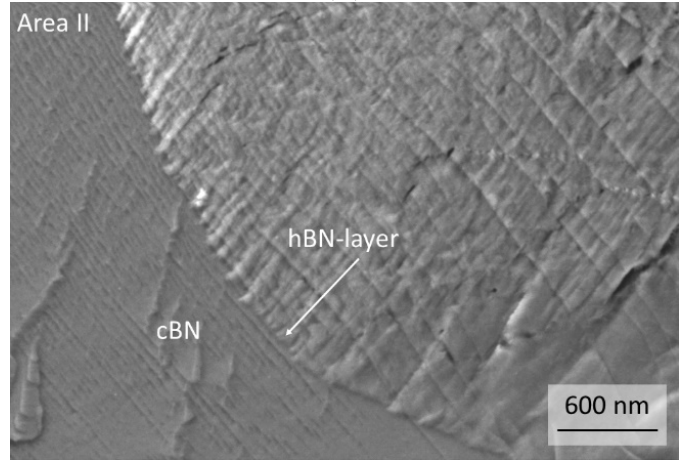

(d)

Figure 9. $(\mathbf{a}, \mathbf{b})$ FESEM micrographs of a particle of the under argon tempered C41 and (c,d) B21 powder with different magnifications. 


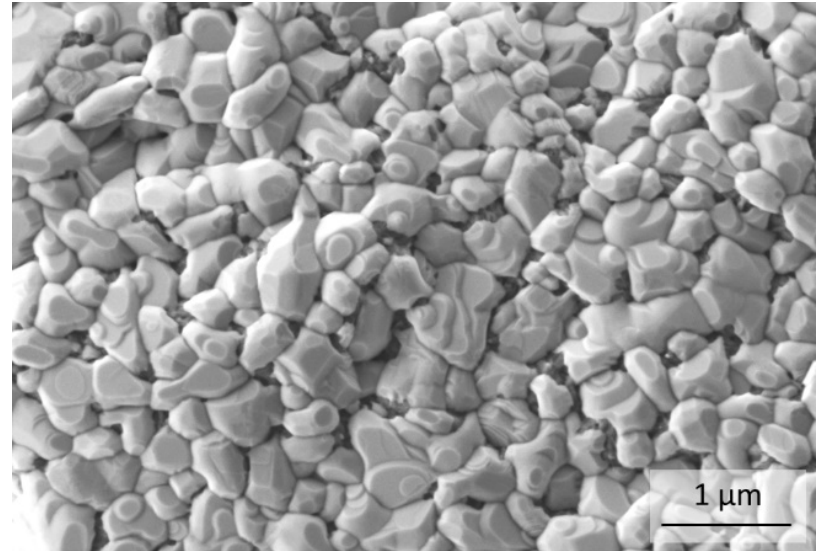

(a)

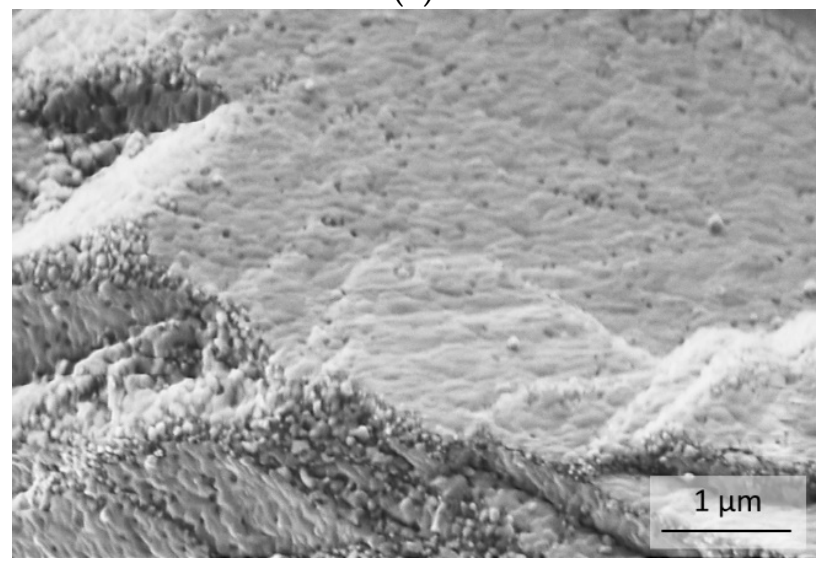

(c)

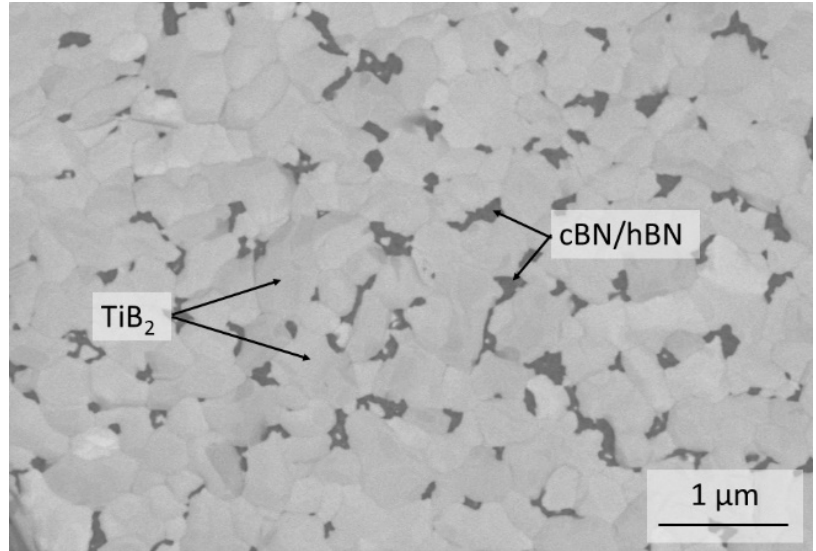

(b)

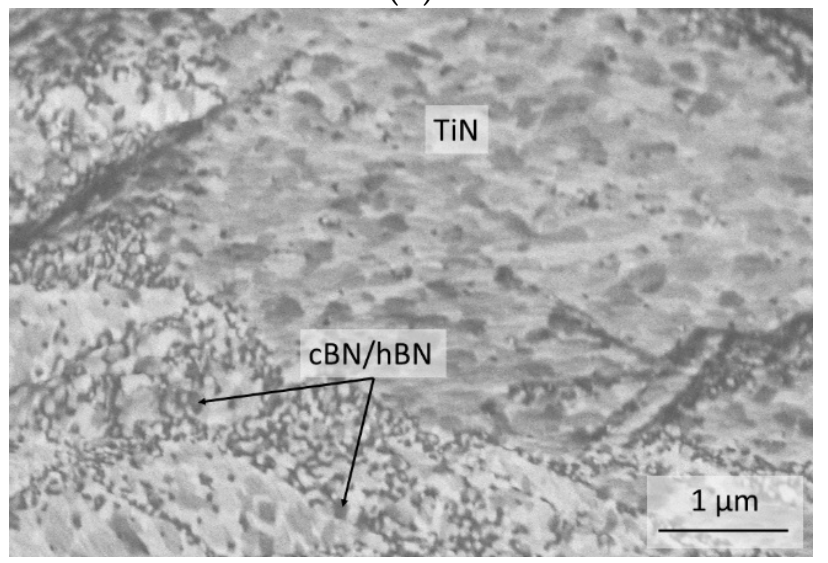

(d)

Figure 10. (a,b) FESEM micrographs of TiN coated cBN particles heat-treated at $1600{ }^{\circ} \mathrm{C}$ under argon and (c,d) under nitrogen (a,c with SE2 detector; $\mathbf{b}, \mathbf{d}$ with ESB detector).

However, Figure 10c,d shows that the TiN phase tempered under a nitrogen atmosphere also undergoes some recrystallization (compare Figure 3e). Additionally, for this coating due to the heat treatment, defects in the coating were formed. However, these are smaller and fewer in comparison with the Ar-treated powder.

The results of the Raman investigations in Figures 11 and 12 clearly reveal the Raman bands of $\mathrm{cBN}$ at 1056 and $1306 \mathrm{~cm}^{-1}$ [23]. The hBN band at $1365 \mathrm{~cm}^{-1}$ has a weak intensity in the heat-treated powder but the band is not observed in the starting powder. The Raman bands of the cBN in the heat-treated powder are shifted to lower wavenumbers. However, the starting powder has also a slight shift compared to the theoretical band positions. It probably has its origin in impurities [41] or/and residual stresses [42].

Figure 12a shows the Raman spectra of the at $1600{ }^{\circ} \mathrm{C}$ under Argon heat-treated powders C41, BTV and BT. The bands of $\mathrm{TiB}_{2}$ at $881 \mathrm{~cm}^{-1}$ [43] and $1573 \mathrm{~cm}^{-1}$ [44] are weak due to a low Raman activity and the low mass fraction of $\mathrm{TiB}_{2}$ in the powders BT and BTV. In all the heat-treated powders a similar weak hBN-band can be observed.

The Raman spectra of heat-treated powders under $\mathrm{N}_{2}$ at $1600^{\circ} \mathrm{C}$ are given in Figure 12c. In contrast to the TiN coated powders annealed under argon the BT powder exhibits Raman bands of TiN in a range of $400-650 \mathrm{~cm}^{-1}[45,46]$. With a focus on the hBN formation, both variants do not show any significant difference in the hBN band (Figure 12b,d). 


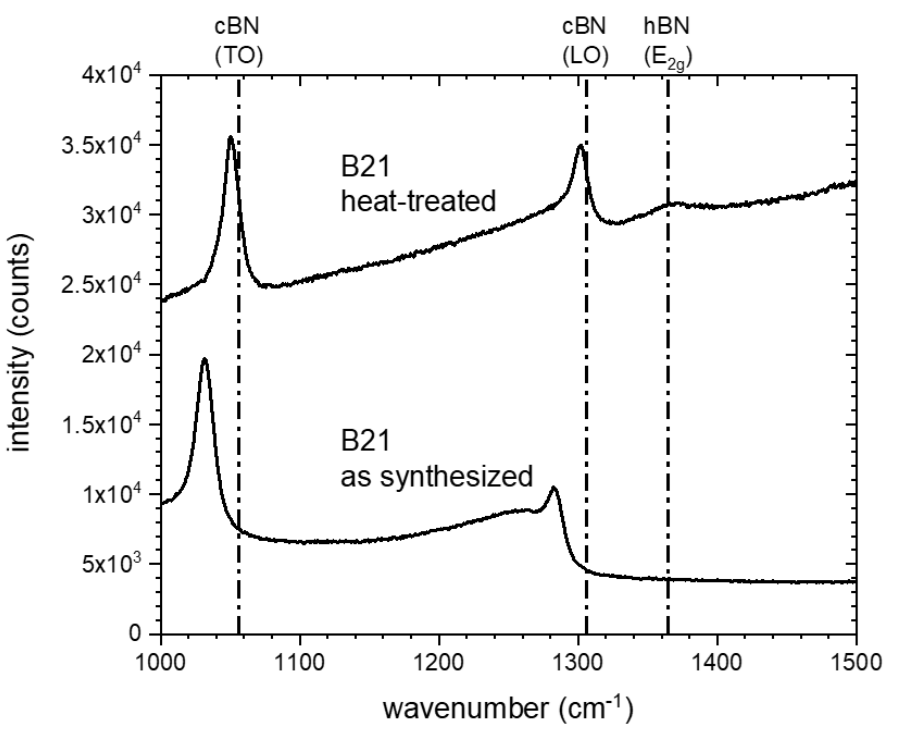

Figure 11. Raman spectra of the under argon tempered $c B N$ powder $B 21$ compared to the initial powder B21.

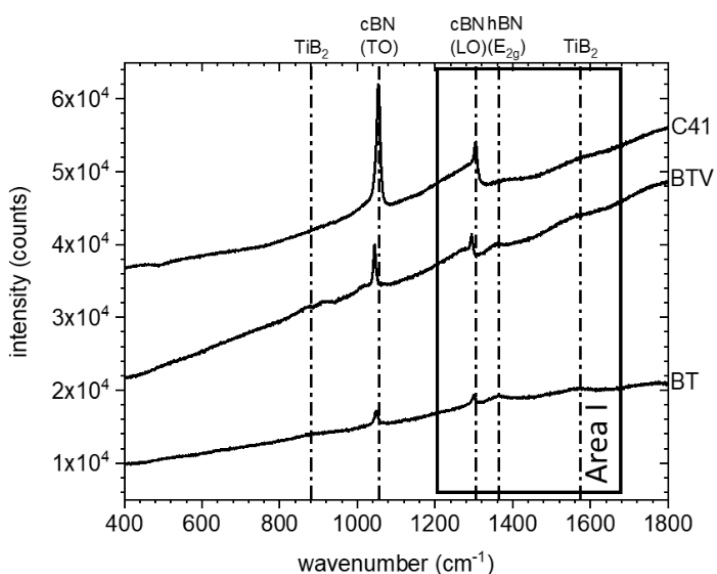

(a)

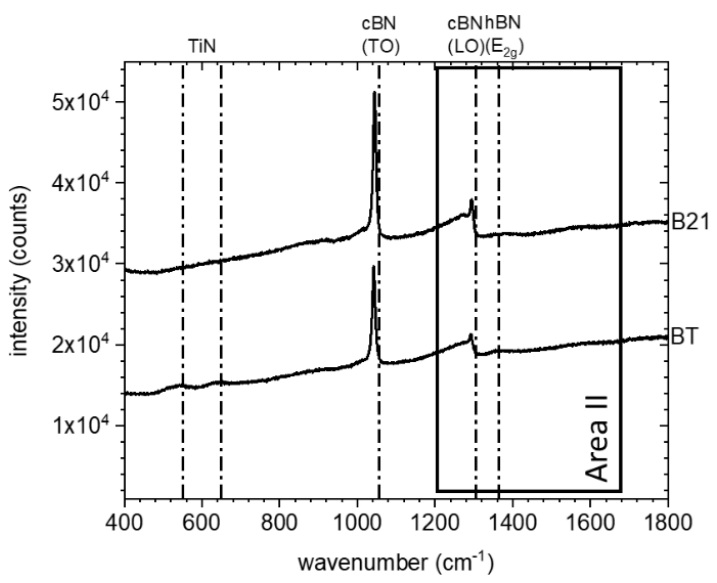

(c)

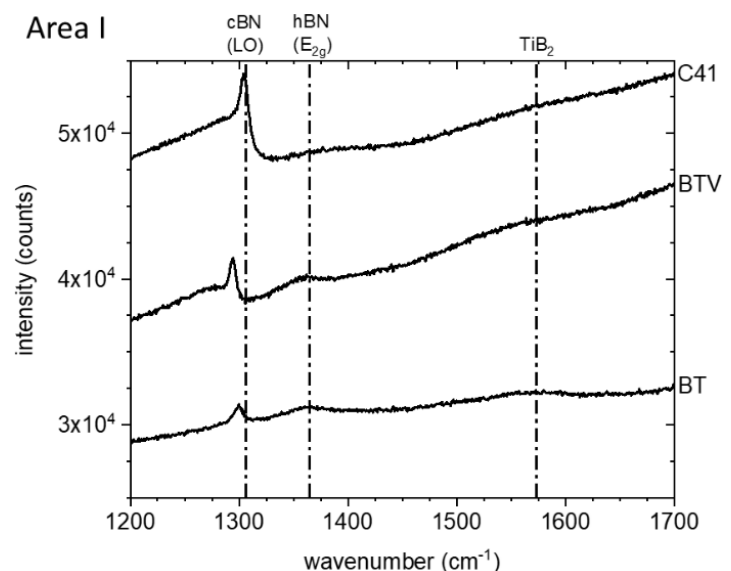

(b)

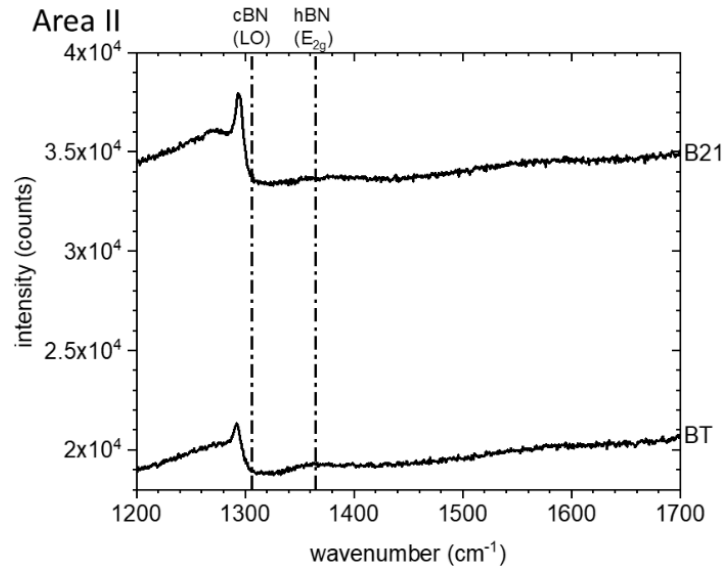

(d)

Figure 12. (a,b) Raman spectra of the heat-treated powders C41, BT and BTV under Ar atmosphere. (c,d) Raman spectra the heat-treated powders B21 and BT under N2 atmosphere. (b,d) are showing a detailed area of the hBN Raman bands in (a,c), respectively. 


\section{Discussion}

The XRD analysis in Figure 2 and the micrographs of the cross-sections of the TiN coated powders BT and BTV in Figure 4 prove a dense and homogenous TiN coating on the $\mathrm{cBN}$ particles.

The higher weight loss during heat treatment in Ar of TiN coated powders BT and BTV in comparison to the uncoated powders (Figures 5 and 6) is caused by the decomposition of the TiN coating. The XRD analysis (Figure 7) reveals the transformation of TiN into $\mathrm{TiB}_{2}$. Such a process does not take place during heat treatment in $\mathrm{N}_{2}$ (Figure 8). The micrographs in Figure 10 prove that the dense coating is decomposed and does not work as a protecting layer of the $\mathrm{cBN}$ grains.

The interaction of TiN with BN can be described by reaction (1) and (2):

$$
\begin{aligned}
& 2 \mathrm{TiN}+4 \mathrm{cBN}=2 \mathrm{TiB}_{2}+3 \mathrm{~N}_{2} \\
& 2 \mathrm{TiN}+4 \mathrm{hBN}=2 \mathrm{TiB}_{2}+3 \mathrm{~N}_{2}
\end{aligned}
$$

It is obvious that the reactions will result in a weight loss due to nitrogen release. Furthermore, it depends on the stability of TiN on the nitrogen pressure. The equilibrium nitrogen pressure for the $\mathrm{cBN} / \mathrm{TiN} / \mathrm{TiB}_{2}$ and the $\mathrm{hBN} / \mathrm{TiN} / \mathrm{TiB}_{2}$ phase mixture was calculated using FACTSAGE 8.0 (Figure 13). The database does not contain the data of cBN. The data in $[1,23]$ for the phase transformation of $\mathrm{c}-\mathrm{BN}$ «h-BN were used for the calculation.

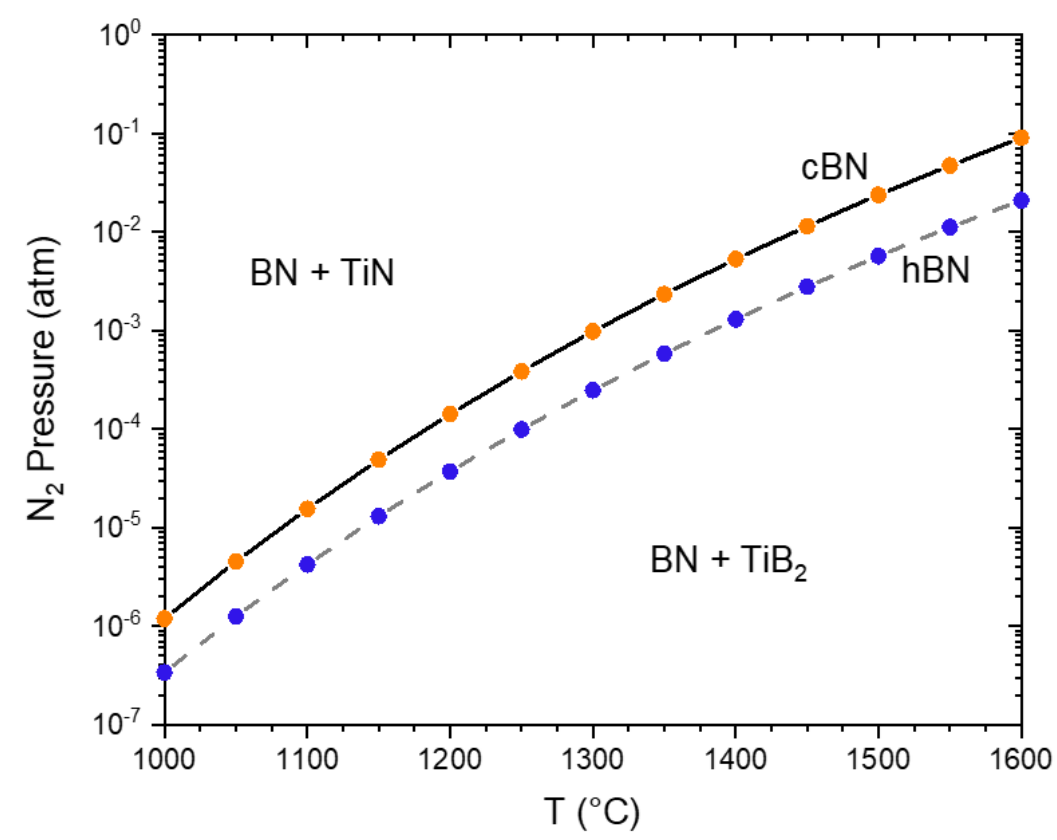

Figure 13. Nitrogen equilibrium pressure as a function of temperature for reaction (1) and (2). The stability area of the $\mathrm{TiN}$ and $\mathrm{TiB}_{2}$ phases are shown.

Above the lines in Figure 13, cBN or hBN is in equilibrium with TiN, below the lines with $\mathrm{TiB}_{2}$. This means if sintering or heat treatment takes place at nitrogen pressure below $2.9 \times 10^{-2} \mathrm{~atm}$ at $1600^{\circ} \mathrm{C}$ the TiN coating would decompose into $\mathrm{TiB}_{2}$ and nitrogen. The data predicts the instability of TiN/cBN for the heat treatment at $1600{ }^{\circ} \mathrm{C}$ in $\mathrm{Ar}$ and the stability of TiN/cBN in $1 \mathrm{~atm}$ nitrogen. This agrees with the experimental observed data of the TG-measurement and microstructural investigations.

Based on the thermodynamics the decomposition of the TiN coating in Ar can take place even at low temperature. The TG measurements reveal a decomposition in argon only above approximately $1200{ }^{\circ} \mathrm{C}$. This could have kinetic reasons and may be additionally caused by the formation of local nitrogen partial pressure due to the decomposition. This pressure could prevent or retard further reactions. This is shown exemplarily in Figure 14. 
The calculation was carried out for a mixture of $98.5 \mathrm{wt}$. \% BN and $1.5 \mathrm{wt}$. \% TiN with three different volumes of the system (defined by the Ar content). This could be a measure of the furnace volume or the gas flow rate multiplied by the time. The graphs show that in small volumes the decomposition is not complete even at $1500^{\circ} \mathrm{C}$, whereas a volume 100 times higher results in the complete decomposition at temperatures up to $1270{ }^{\circ} \mathrm{C}$. On the other hand, the examples show that due to the low nitrogen equilibrium pressure decomposition of TiN practically does not take place at temperatures below $1050{ }^{\circ} \mathrm{C}$.

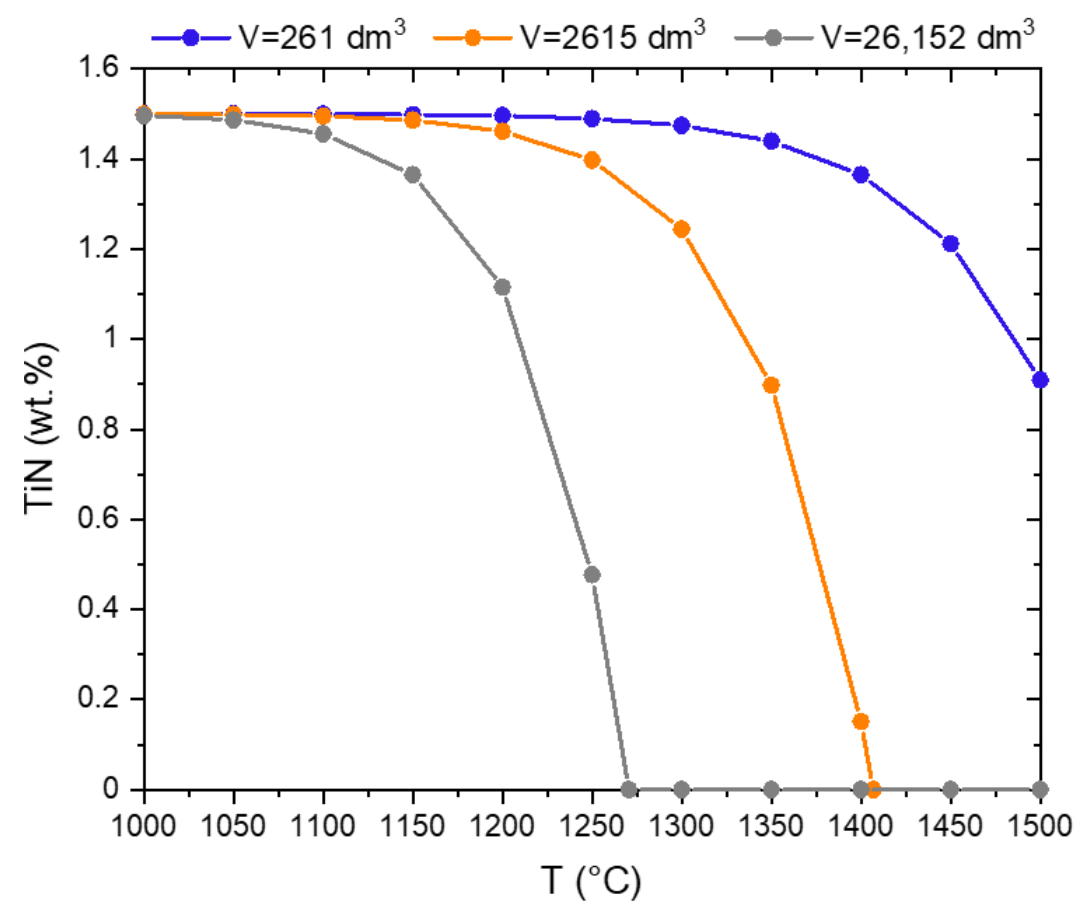

Figure 14. Decomposition of TiN in the mixture of ( $98.5 \mathrm{wt}$ \% $\% \mathrm{hBN}$ and $1.5 \mathrm{wt}$. \% TiN) according to reaction (2) as a function of temperature and the volume of the system (volume given at $1000{ }^{\circ} \mathrm{C}$ in $\left.(\mathrm{dm})^{3}\right)$.

The determined phase composition in the starting coated powders (see Table 1) can be used together with Equations (1) and (2) to calculate the mass loss during the heat treatment and to predict the amount of $\mathrm{TiB}_{2}$. The mass loss corresponds to the nitrogen release in Equations (1) and (2). The results of the calculations based on the TiN content measured by XRD are given in Table 3 . The results are in good agreement with the observed weight losses and the measured amount of $\mathrm{TiB}_{2}$ in the heat-treated powder. This indicates that the interaction of TiN with $\mathrm{BN}$ is the main process responsible for the weight loss. Additionally, reactions with residual oxygen or moisture can play a role. However, in nitrogen with a similar purity, these effects result in a much lower weight loss.

Table 3. By XRD analysis measured and calculated phase contents of $\mathrm{TiN}$ and $\mathrm{TiB}_{2}$ in the initial and in the Ar heat-treated cBN powders and measured and calculated weight loss during heat treatment according to reaction (1) and (2).

\begin{tabular}{cccccc}
\hline $\begin{array}{c}\text { TiN Coated } \\
\text { cBN-Powder }\end{array}$ & $\begin{array}{c}\text { Measured } \\
\text { TiN Content before } \\
\text { TGA (wt. \%) }\end{array}$ & $\begin{array}{c}\text { Measured } \\
\text { TiB }_{2} \text { Content after } \\
\text { TGA (wt. \%) }\end{array}$ & $\begin{array}{c}\text { Calculated TiB } \\
\text { Content (wt. \%) }\end{array}$ & $\begin{array}{c}\text { Calculated Weight } \\
\text { Loss (wt. \%) }\end{array}$ & $\begin{array}{c}\text { Loss of Mass after } \\
\text { TGA (wt. \%) }\end{array}$ \\
\hline BT & $2.3 \pm 0.1$ & $2.8 \pm 0.1$ & 2.6 & 1.56 & 1.58 \\
BTV & $1.3 \pm 0.1$ & $1.8 \pm 0.1$ & 1.5 & 0.88 & 1.01 \\
\hline
\end{tabular}

The investigations show that the TiN-coating on cBN particles could be a protective one only if a nitrogen partial pressure is formed on the surface. Otherwise, the formation of the $\mathrm{TiB}_{2}$ result in a destruction of the initially continuous TiN-coating. 
However, very thin fine-grained TiN coatings, produced by ALD, could also undergo recrystallization at high temperatures in $\mathrm{N}_{2}$ despite the fact that they do not react with cBN. This recrystallization could also result in some damage to the coating (Figure 10d).

\section{Conclusions}

The investigation of the thermal stability of TiN coated cBN particles using thermogravimetric, phase and microstructural analysis reveal that,

- The stability of TiN coatings on cBN particles strongly depend on the nitrogen pressure. The decomposition into $\mathrm{TiB}_{2}$ was observed in $\mathrm{Ar}$ at temperatures above approximately $1200{ }^{\circ} \mathrm{C}$. This reaction results in the formation of pores in the originally dense coating. Therefore, the layer could not more work as a protection layer.

- In a nitrogen atmosphere (1 atm pressure) no interaction of TiN with cBN was observed up to $1600^{\circ} \mathrm{C}$. However, the investigated very thin fine-grained TiN coatings, produced by ALD, showed after the heat treatment at $1600^{\circ} \mathrm{C}$ a recrystallization, resulting also in very fine pores. Further investigations are necessary to clarify whether these processes also take place at $1300-1400{ }^{\circ} \mathrm{C}$, at which composites are typically sintered with cBN. Additionally, the influence of the thickness and crystallite size of the coating needs further investigations.

- The observed results could be predicted by the thermodynamic calculations.

The results form a basis for the use of TiN-protective coatings to control the conversion of $\mathrm{cBN}$ in $\mathrm{hBN}$ accelerated by liquid phases during sintering of composites and for the optimization of the compaction processes. The coating is stable above temperatures of $1100-1200^{\circ} \mathrm{C}$ only if a nitrogen partial pressure is higher than $1.5 \times 10^{-4} \mathrm{~atm}$ or $>1 \times 10^{-3}$ atm at $1300{ }^{\circ} \mathrm{C}$ (Figure 13). In molds of the SPS or hot presses with a small volume and a hindered gas exchange with the furnace chamber the decomposition of the TiN coating during densification can be stabilized by this reason. Additionally, a small amount of residual gas could have a stabilizing effect.

However, further investigations have to be carried out to investigate the stability of the TiN coatings even in the thermodynamic stable region due to the fact, that nanocrystalline TiN-coatings can recrystallize during sintering or react with the matrix. At least, coatings with thicknesses up to $50 \mathrm{~nm}$ - produced by ALD and investigated here-were not stable at $1600{ }^{\circ} \mathrm{C}$ in nitrogen. The observed recrystallization resulted in small pores which might increase the conversion of $\mathrm{cBN}$ into $\mathrm{hBN}$ due to interaction with oxide liquids. Therefore, it is important to determine the necessary thickness and crystallite size of the TiN coating at the different sintering temperatures that are required to prevent $\mathrm{cBN}-\mathrm{hBN}$ conversion.

The use of such coated cBN particles as abrasives or in composites additionally requires the investigation of the adhesion and wear resistance of the coated powders. These will be addressed as next steps.

Author Contributions: Conceptualization, A.-K.W. and M.H.; Methodology, A.-K.W. and M.H.; Investigation, B.H. and T.G.; Data Curation, B.H.; Writing-Original Draft Preparation, B.H.; WritingReview \& Editing, A.-K.W., T.G. and M.H.; Visualization, B.H.; Supervision, A.-K.W.; Project Administration, A.-K.W.; Funding Acquisition, A.-K.W. All authors have read and agreed to the published version of the manuscript.

Funding: This research was funded by the Deutsche Forschungsgemeinschaft (DFG), project no. 429418801.

Institutional Review Board Statement: Not applicable.

Informed Consent Statement: Not applicable.

Data Availability Statement: The data presented in this study are available on request from the corresponding author.

Acknowledgments: The hot gas extraction was carried out at the Fraunhofer Institut für Fertigungstechnik und Angewandte Materialforschung IFAM (Dresden, Germany). The authors thanks Björn Matthey, M. Höhn, Mareike Herrmann and Sylvia Szokup at the Fraunhofer (IKTS) for their support 
for the analysis of the microstructure and the preparation of the TiN coating. Open Access Funding by the Publication Fund of the TU Dresden.

Conflicts of Interest: The authors declare no conflict of interest. The funders had no role in the design of the study; in the collection, analyses, or interpretation of data; in the writing of the manuscript, or in the decision to publish the results.

\section{References}

1. Wolfrum, A.-K. Verdichtung und Eigenschaften von Hartstoffverstärkten Siliciumnitridwerkstoffen. Ph.D. Dissertation, Technische Universität Dresden, Dresden, Germany, 2019.

2. Hotta, M.; Goto, T. Preparation of $\beta$ SiAlON-cBN composites by spark plasma sintering. Key Eng. Mater. 2008, 403, $241-242$. [CrossRef]

3. Michalski, A.; Rosiński, M.; Płocińska, M.; Szawłowski, J. Synthesis and characterization of cBN/WCCo composites obtained by the pulse plasma sintering (PPS) method. IOP Conf. Ser. 2011, 18, 202016. [CrossRef]

4. Zhang, J.; Tu, R.; Goto, T. Densification, microstructure and mechanical properties of $\mathrm{SiO}_{2}-\mathrm{cBN}$ composites by spark plasma sintering. Ceram. Int. 2012, 38, 351-356. [CrossRef]

5. Zhang, J.F.; Tu, R.; Goto, T. Spark plasma sintering and characterization of WC-Co-cBN composites. Key Eng. Mater. 2014, 616, 194-198. [CrossRef]

6. Klimczyk, P.; Wyżga, P.; Cyboroń, J.; Laszkiewicz-Łukasik, J.; Podsiadło, M.; Cygan, S.; Jaworska, L. Phase stability and mechanical properties of $\mathrm{Al}_{2} \mathrm{O}_{3}-\mathrm{cBN}$ composites prepared via spark plasma sintering. Diam. Relat. Mater. 2020, 104, 107762. [CrossRef]

7. Garrett, J.C.; Sigalas, I.; Herrmann, M.; Olivier, E.J.; O'Connell, J.H. cBN reinforced Y- $\alpha$-SiAlON composites. J. Eur. Ceram. Soc. 2013, 33, 2191-2198. [CrossRef]

8. Yuan, Y.; Cheng, X.; Chang, R.; Li, T.; Zang, J.; Wang, Y.; Yu, Y.; Lu, J.; Xu, X. Reactive sintering cBN-Ti-Al composites by spark plasma sintering. Diam. Relat. Mater. 2016, 69, 138-143. [CrossRef]

9. Zhang, J.; Tu, R.; Goto, T. Cubic boron nitride-containing ceramic matrix composites for cutting tools. Adv. Ceram. Matrix Compos. 2014, 570-586. [CrossRef]

10. Scheffler, M. Zukunftspotenziale von Hochleistungskeramiken: Expertenstudie; DKG: Köln, Germany, 2014; ISBN 978-3-00-045777-7.

11. Guillon, O.; Gonzalez-Julian, J.; Dargatz, B.; Kessel, T.; Schierning, G.; Räthel, J.; Herrmann, M. Field-assisted sintering technology/spark plasma sintering: Mechanisms, materials, and technology developments. Adv. Eng. Mater. 2014, 16, 830-849. [CrossRef]

12. Bundy, F.P.; Wentorf, R.H. Direct transformation of hexagonal boron nitride to denser forms. J. Chem. Phys. 1963, 38, 1144-1149. [CrossRef]

13. Corrigan, F.R.; Bundy, F.P. Direct transitions among the allotropic forms of boron nitride at high pressures and temperatures. J. Chem. Phys. 1975, 63, 3812. [CrossRef]

14. Vereshchagin, L.F.; Gladkaya, I.S.; Dubitskii, G.A.; Slesarev, V.N. Synthesis of cubic boron nitride single crystals in systems containing hydrogen. Izv. Akad. Nauk. SSSR Neorg. Mater. 1979, 15, 256-259.

15. Maki, J.; Ikawa, H.; Fukunaga, O. Phase equilibrium between cubic and hexagonal boron nitride. In Proceedings of the 2nd New Diamond Science and Technology International Conference, Washington, DC, USA, 23-27 September 1990; pp. 1051-1055.

16. Solozhenko, V.L. Boron nitride phase diagram. State of the art. High Press. Res. 1995, 13, 199-214. [CrossRef]

17. Solozhenko, V.L.; Turkevich, V.Z. Thermoanalytical study of the polymorphic transformation of cubic into graphite-like boron nitride. J. Therm. Anal. 1992, 38, 1181-1188. [CrossRef]

18. Solozhenko, V.L. Inverse drop-calorimetry. A study of metastable and nonequilibrium phases. Thermochim. Acta 1993, 218, 395-400. [CrossRef]

19. Solozhenko, V.L. Thermodynamics of dense boron nitride modifications and a new phase P.,T diagram for BN. Thermochim. Acta 1993, 218, 221-227. [CrossRef]

20. Solozhenko, L.; Turkevich, V.Z.; Holzapfel, W.B. Refined phase diagram of boron nitride. J. Phys. Chem. B 1999, 103, $2903-2905$. [CrossRef]

21. Will, G.; Nover, G.; von der Gönna, J. New experimental results on the phase diagram of boron nitride. J. Solid State Chem. 2000, 154, 280-285. [CrossRef]

22. Fukunaga, O. The equilibrium phase boundary between hexagonal and cubic boron nitride. Diam. Relat. Mater. 2000, 9, 7-12. [CrossRef]

23. Wolfrum, A.-K.; Matthey, B.; Michaelis, A.; Herrmann, M. On the stability of c-BN-reinforcing particles in ceramic matrix materials. Materials 2018, 11, 255. [CrossRef]

24. Cahill, J.T.; Du Frane, W.L.; Sio, C.K.; King, G.C.S.; Soderlind, J.C.; Lu, R.; Worsley, A.; Kuntza, J.D. Transformation of boron nitride from cubic to hexagonal under 1-atm helium. Diam. Relat. Mater. 2020, 109, 108078. [CrossRef]

25. Irshad, H.M.; Ahmed, B.A.; Ehsan, M.A.; Khan, T.I.; Laoui, T.; Yousaf, M.R.; Ibrahim, A.; Hakeem, A.S. Investigation of the structural and mechanical properties of micro-/nano-sized $\mathrm{Al}_{2} \mathrm{O}_{3}$ and $\mathrm{cBN}$ composites prepared by spark plasma sintering. Ceram. Int. 2017, 43, 10645-10653. [CrossRef] 
26. Irshad, H.M.; Ahmed, B.A.; Ehsan, M.A.; Khan, T.I.; Laoui, T.; Yousaf, M.R.; Ibrahim, A.; Hakeem, A.S. Tribological behaviour of alumina-based nanocomposites reinforced with uncoated and Ni-coated cubic boron nitride. J. Mater. Res. Technol. 2019, 8 , 5066-5079. [CrossRef]

27. Zhang, J.; Tu, R.; GOTO, T. Evaluation of CVD-Deposited $\mathrm{SiO}_{2}$ as a sintering aid for cubic boron nitride consolidated with alumina by spark plasma sintering. J. Am. Ceram. Soc. 2012, 95, 2827-2832. [CrossRef]

28. Hotta, M.; Goto, T. Spark plasma sintering of TiN-cubic BN composites. J. Ceram. Soc. Jpn. 2010, 118, 137-140. [CrossRef]

29. Hotta, M.; Goto, T. Densification and microstructure of $\mathrm{Al}_{2} \mathrm{O}_{3}-\mathrm{cBN}$ composites prepared by spark plasma sintering. J. Ceram. Soc. Jpn. 2008, 116, 744-748. [CrossRef]

30. Hotta, M.; Goto, T. Spark plasma sintering of $\beta$ SiAlON-cBN composite. Mater. Sci. Forum 2007, 561-565, 599-602. [CrossRef]

31. Kitiwan, M.; Ito, A.; Goto, T. Phase transformation and densification of hBN-TiN composites fabrication by spark plasma sintering. Key Eng. Mater. 2012, 508, 52-55. [CrossRef]

32. Xie, H.; Deng, F.; Wang, H.; Liu, J.; Han, S.; Feng, F. Study of the proportioning design method and mechanical properties of a cBN-TiN composite. Int. J. Refract. Met. Hard Mater. 2020, 89, 105209. [CrossRef]

33. Umer, M.A.; Sub, P.H.; Lee, D.J.; Ryu, H.J.; Hong, S.H. Polycrystalline cubic boron nitride sintered compacts prepared from nanocrystalline TiN coated cBN powder. Mater. Sci. Eng. 2012, 552, 151-156. [CrossRef]

34. Umer, M.A.; Park, H.S.; Lee, D.J.; Ryu, H.J.; Hong, S.H. A sol-gel route to nanocrystalline TiN coated cubic boron nitride particles. J. Alloys Compd. 2011, 509, 9764-9769. [CrossRef]

35. George, S.M. Atomic layer deposition: An overview. Chem. Rev. 2010, 110, 111-131. [CrossRef]

36. Longrie, D.; Deduytsche, D.; Detavernier, C. Reactor concepts for atomic layer deposition on agitated particles: A review. J. Vac. Sci. Technol. A 2014, 32, 10802. [CrossRef]

37. Longrie, D.; Deduytsche, D.; Haemers, J.; Smet, P.F.; Driesen, K.; Detavernier, C. Thermal and plasma-enhanced atomic layer deposition of TiN using TDMAT and $\mathrm{NH}_{3}$ on particles agitated in a rotary reactor. ACS Appl. Mater. Interfaces 2014, 6, 7316-7324. [CrossRef]

38. Didden, A.; Hillebrand, P.; Wollgarten, M.; Dam, B.; van de Krol, R. Deposition of conductive TiN shells on $\mathrm{SiO}_{2}$ nanoparticles with a fluidized bed ALD reactor. J. Nanopart. Res. 2016, 18, 35. [CrossRef]

39. Hoehn, S.; Sempf, K.; Herrmann, M. Artefact-free preparation and characterisation of ceramic materials and interfaces. Ceram. Forum Int. 2011, 88, E16-E20.

40. Bale, C.W.; Bélisle, E.; Chartrand, P.; Decterov, S.A.; Eriksson, G.; Gheribi, A.E.; Hack, K.; Jung, I.H.; Kang, Y.B.; Melançon, J.; et al. FactSage thermochemical software and databases, 2010-2016. Calphad 2016, 54, 35-53. [CrossRef]

41. Tuschel, D. Effect of dopants or impurities on the raman spectrum of the host crystal. Spectroscopy (St. Monica) 2017, 32, 13-18.

42. Jana, M.; Singh, R.N. A study of evolution of residual stress in single crystal silicon electrode using Raman spectroscopy. Appl. Phys. Lett. 2017, 111, 63901. [CrossRef]

43. Wdowik, U.D.; Twardowska, A.; Rajchel, B. Vibrational spectroscopy of binary titanium borides: First-principles and experimental studies. Adv. Condens. Matter. Phys. 2017, 2017, 1-9. [CrossRef]

44. Gu, L.; Wang, T.; Zhang, W.; Liang, G.; Gu, A.; Yuan, L. Low-cost and facile fabrication of titanium dioxide coated oxidized titanium diboride-epoxy resin composites with high dielectric constant and extremely low dielectric loss. RSC Adv. 2013, 3, 7071. [CrossRef]

45. Gall, D.; Stoehr, M.; Greene, J.E. Vibrational modes in epitaxial $\mathrm{Ti}_{1-x} \mathrm{Sc}_{\mathrm{x}} \mathrm{N}(001)$ layers: An ab initio calculation and Raman spectroscopy study. Phys. Rev. B 2001, 64, 174302. [CrossRef]

46. Cheng, Y.H.; Tay, B.K.; Lau, S.P.; Kupfer, H.; Richter, F. Substrate bias dependence of Raman spectra for TiN films deposited by filtered cathodic vacuum arc. J. Appl. Phys. 2002, 92, 1845-1849. [CrossRef] 